\title{
Screening of a custom-designed acid fragment library identifies 1-phenylpyrroles and 1- phenylpyrrolidines as inhibitors of Notum carboxylesterase activity.
}

\section{SUPPORTING INFORMATION}

William Mahy, ${ }^{1}$ Mikesh Patel, ${ }^{2}$ David Steadman, ${ }^{1}$ Hannah L. Woodward, ${ }^{1}$ Benjamin N. Atkinson, ${ }^{1}$ Fredrik Svensson, ${ }^{1,3}$ Nicky Willis, ${ }^{1}$ Alister Flint, ${ }^{2}$ Dimitra Papatheodorou, ${ }^{4}$ Yuguang Zhao, ${ }^{5}$ Luca Vecchia, ${ }^{5}$ Reinis R. Ruza, ${ }^{5}$ James Hillier, ${ }^{5}$ Sarah Frew, ${ }^{1}$ Amy Monaghan, ${ }^{1}$ Artur Costa, ${ }^{1}$ Magda Bictash, ${ }^{1}$ Magnus W. Walter, ${ }^{6}$ E. Yvonne Jones, ${ }^{5}$ Paul V. Fish. ${ }^{1,2, *}$

${ }^{1}$ Alzheimer's Research UK UCL Drug Discovery Institute, University College London, Cruciform Building, Gower Street, London, WC1E 6BT, U.K.

${ }^{2}$ Department of Chemistry, University College London, 20 Gordon Street, London, WC1H OAJ, U.K.

${ }^{3}$ The Francis Crick Institute, 1 Midland Road, Kings Cross, London NW1 1AT, U.K.

${ }^{4}$ UCL School of Pharmacy, University College London, 29-39 Brunswick Square, Bloomsbury, London WC1N 1AX, U.K.

${ }^{5}$ Division of Structural Biology, Wellcome Centre for Human Genetics, University of Oxford, The Henry Wellcome Building for Genomic Medicine, Roosevelt Drive, Oxford, OX3 7BN, U.K.

${ }^{6}$ Eli Lilly, Erl Wood Manor, Windlesham, Surrey, GU20 6PH, U.K. 
Table of contents:

Page S3 Table S1. Acid fragment library of 250 compounds.

Page S9 Table S2. X-ray structure determination: PDB codes, data collection and refinement.

Page S11 Figure S1. Weakly active pyrrole S1 and inactive pyrrolidine-3-carboxylic acid S2 present in the acid fragment library.

Page S12 Figure S2. Inhibition of Notum activity of additional pyrroles and pyrrolidines.

Page S14 Figure S3: Spectroscopic and analytical data for 26.

Page S21 Figure S4: ADME data for compounds 20z, 26, 28e and 30.

Page S25 Methods. Notum protein production, crystallization, compound soaking, data collection and structure determination.

Page S26 SI References 
Table S1. Acid fragment library of 250 compounds.

Purchased from Enamine:

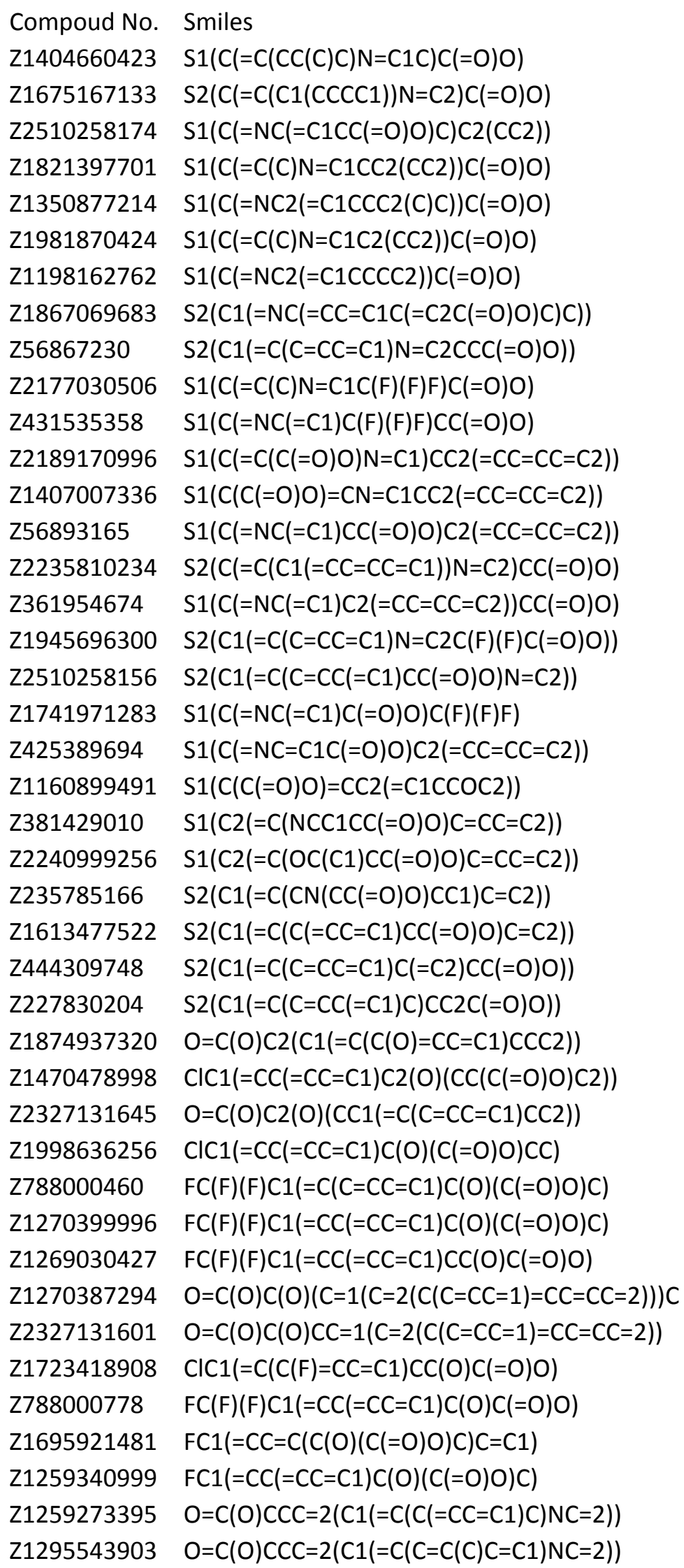


Z1309300216

Z1318356910

Z1270400011

Z336481702

Z336481624

Z1622825634

Z220533672

Z336481634

Z1172068152

Z1171978802

Z1255523324

Z1207150502

Z1269219664

Z1171979221

Z168883466

Z197513748

Z1172115956

Z2584270329

Z56913182

Z1259399760

Z1704732732

Z56776913

Z1696871288

Z274568060

Z2379087815

Z1695729059

Z1171978885

Z1270387211

Z2010010272

Z1255368087

Z85922627

Z1665392902

Z1945695955

Z1266933930

Z982129788

Z1665393265

Z2096659384

Z57065721

Z1509663781

Z228589446

Z57080376

Z1255523379

Z1702888505

Z56756342

Z351339470

Z1259339964
$\mathrm{O}=\mathrm{C}(\mathrm{O}) \mathrm{CCC}=2(\mathrm{C} 1(=\mathrm{C}(\mathrm{C}=\mathrm{CC}(=\mathrm{C} 1) \mathrm{C}) \mathrm{NC}=2))$

$\mathrm{O}=\mathrm{C}(\mathrm{O}) \mathrm{CCC}=2(\mathrm{C} 1(=\mathrm{C}(\mathrm{C}=\mathrm{CC}=\mathrm{C} 1 \mathrm{NC}=2) \mathrm{C}))$

$\mathrm{O}=\mathrm{C}(\mathrm{O}) \mathrm{CC}=2(\mathrm{C} 1(=\mathrm{C}(\mathrm{C}(=\mathrm{CC}=\mathrm{C} 1) \mathrm{CC}) \mathrm{NC}=2))$

$\mathrm{O}=\mathrm{C}(\mathrm{O}) \mathrm{CC}=2(\mathrm{C} 1(=\mathrm{C}(\mathrm{C}=\mathrm{CC}(=\mathrm{C} 1) \mathrm{C}) \mathrm{NC}=2 \mathrm{C}))$

$\mathrm{FC} 2(=\mathrm{CC} 1(=\mathrm{C}(\mathrm{NC}(=\mathrm{C} 1 \mathrm{CC}(=\mathrm{O}) \mathrm{O}) \mathrm{C}) \mathrm{C}=\mathrm{C} 2))$

$\mathrm{O}=\mathrm{C}(\mathrm{O}) \mathrm{CCC} 2(=\mathrm{CC} 1(=\mathrm{C}(\mathrm{NC}=\mathrm{C} 1) \mathrm{C}=\mathrm{C} 2))$

$\mathrm{O}=\mathrm{C}(\mathrm{O}) \mathrm{CCC}=2(\mathrm{C} 1(=\mathrm{C}(\mathrm{C}=\mathrm{CC}=\mathrm{C} 1) \mathrm{NC}=2))$

$\mathrm{O}=\mathrm{C}(\mathrm{O}) \mathrm{CC}=2(\mathrm{C} 1(=\mathrm{C}(\mathrm{C}=\mathrm{CC}=\mathrm{C} 1) \mathrm{NC}=2 \mathrm{C}))$

$\mathrm{O}=\mathrm{C}(\mathrm{O}) \mathrm{CC}=2(\mathrm{C} 1(=\mathrm{C}(\mathrm{C}=\mathrm{C}(\mathrm{C}) \mathrm{C}=\mathrm{C} 1) \mathrm{NC}=2))$

$\mathrm{O}=\mathrm{C}(\mathrm{O}) \mathrm{CC}=2(\mathrm{C} 1(=\mathrm{C}(\mathrm{C}=\mathrm{CC}=\mathrm{C} 1 \mathrm{NC}=2) \mathrm{C}))$

$\mathrm{O}=\mathrm{C}(\mathrm{O}) \mathrm{CC}=2(\mathrm{C} 1(=\mathrm{C}(\mathrm{C}(=\mathrm{CC}=\mathrm{C} 1) \mathrm{C}) \mathrm{NC}=2))$

$F C(F)(F) C=1(N C(C)=C(C=1) C(=0) 0)$

$\mathrm{CIC} 2(=\mathrm{CC} 1(=\mathrm{C}(\mathrm{NC}(=\mathrm{C} 1) \mathrm{CC}(=0) \mathrm{O}) \mathrm{C}=\mathrm{C} 2))$

$\mathrm{ClC} 2(=\mathrm{CC}=1(\mathrm{NC}=\mathrm{C}(\mathrm{C}=1 \mathrm{C}=\mathrm{C} 2) \mathrm{CC}(=0) 0))$

$\mathrm{O}=\mathrm{C}(\mathrm{O}) \mathrm{C}=2(\mathrm{C} 1(=\mathrm{C}(\mathrm{C}=\mathrm{CC}=\mathrm{C} 1) \mathrm{NC}=2 \mathrm{C}))$

$\mathrm{O}=\mathrm{C}(\mathrm{O}) \mathrm{C}=1(\mathrm{NC}=2(\mathrm{C}=\mathrm{C}(\mathrm{C}) \mathrm{C}=\mathrm{CC}=2(\mathrm{C}=1)))$

$\mathrm{O}=\mathrm{C}(\mathrm{O}) \mathrm{C}=2(\mathrm{C} 1(=\mathrm{C}(\mathrm{C}=\mathrm{CC}=\mathrm{C} 1 \mathrm{NC}=2) \mathrm{C}))$

$\mathrm{O}=\mathrm{C}(\mathrm{O}) \mathrm{CC} 2(=\mathrm{CC} 1(=\mathrm{C}(\mathrm{NC}=\mathrm{C} 1) \mathrm{C}=\mathrm{C} 2))$

$\mathrm{O}=\mathrm{C}(\mathrm{O}) \mathrm{CC}=2(\mathrm{C} 1(=\mathrm{C}(\mathrm{C}=\mathrm{CC}=\mathrm{C} 1) \mathrm{NC}=2))$

$\mathrm{FC}(\mathrm{F})(\mathrm{F}) \mathrm{C}=1(\mathrm{NC}(\mathrm{C}(=\mathrm{O}) \mathrm{O})=\mathrm{CC}=1)$

$\mathrm{O}=\mathrm{C}(\mathrm{O}) \mathrm{CC}=2(\mathrm{C} 1(=\mathrm{C}(\mathrm{C}=\mathrm{CC}=\mathrm{C} 1) \mathrm{OC}=2 \mathrm{C}))$

$\mathrm{O}=\mathrm{C}(\mathrm{O}) \mathrm{CC}=2(\mathrm{C} 1(=\mathrm{C}(\mathrm{C}=\mathrm{C}(\mathrm{C}) \mathrm{C}=\mathrm{C} 1) \mathrm{OC}=2))$

$\mathrm{O}=\mathrm{C}(\mathrm{O}) \mathrm{C}=2(\mathrm{C} 1(=\mathrm{C}(\mathrm{C}=\mathrm{CC}=\mathrm{C} 1) \mathrm{OC}=2 \mathrm{C}))$

$\mathrm{O}=\mathrm{C}(\mathrm{O}) \mathrm{C}=1(\mathrm{OC}=2(\mathrm{C}=\mathrm{CC}(=\mathrm{CC}=2(\mathrm{C}=1)) \mathrm{C}))$

$\mathrm{O}=\mathrm{C}(\mathrm{O}) \mathrm{C}=2(\mathrm{C} 1(=\mathrm{C}(\mathrm{C}(=\mathrm{CC}=\mathrm{C} 1) \mathrm{C}) \mathrm{OC}=2))$

$\mathrm{FC} 2(=\mathrm{CC}=1(\mathrm{OC}=\mathrm{C}(\mathrm{C}=1 \mathrm{C}=\mathrm{C} 2) \mathrm{CC}=0) 0))$

$\mathrm{O}=\mathrm{C}(\mathrm{O}) \mathrm{CC}=1(\mathrm{OC}=2(\mathrm{C}=\mathrm{CC}=\mathrm{CC}=2(\mathrm{C}=1)))$

$\mathrm{O}=\mathrm{C}(\mathrm{O}) \mathrm{C} 2(=\mathrm{NC} 1(=\mathrm{C}(\mathrm{CCCC} 1) \mathrm{C}=\mathrm{C} 2))$

$\mathrm{O}=\mathrm{C}(\mathrm{O}) \mathrm{C} 1(=\mathrm{NC}=\mathrm{C} 2(\mathrm{CCCCC} 2(=\mathrm{C} 1)))$

$\mathrm{O}=\mathrm{C}(0) \mathrm{C} 2(\mathrm{C} 1(=\mathrm{NC}=\mathrm{CC}=\mathrm{C} 1 \mathrm{CCC} 2))$

$\mathrm{O}=\mathrm{C}(\mathrm{O}) \mathrm{CCC} 2(=\mathrm{NC}=1(\mathrm{C}=\mathrm{CC}=\mathrm{CC}=1) \mathrm{C}=\mathrm{C} 2))$

$\mathrm{O}=\mathrm{C}(\mathrm{O}) \mathrm{C}(\mathrm{C} 2(=\mathrm{NC}=1(\mathrm{C}=\mathrm{CC}=\mathrm{CC}=1) \mathrm{C}=\mathrm{C} 2))) \mathrm{C}$

$\mathrm{O}=\mathrm{C}(\mathrm{O}) \mathrm{CCC}=1(\mathrm{C}=\mathrm{NC} 2(=\mathrm{CC}=\mathrm{CC}=\mathrm{C} 2(\mathrm{C}=1)))$

$\mathrm{O}=\mathrm{C}(\mathrm{O}) \mathrm{CCC}=1(\mathrm{C}=2(\mathrm{C}(\mathrm{N}=\mathrm{CC}=1)=\mathrm{CC}=\mathrm{CC}=2))$

$\mathrm{O}=\mathrm{C}(\mathrm{O}) \mathrm{C}(\mathrm{C}=1(\mathrm{C}=\mathrm{NC} 2(=\mathrm{CC}=\mathrm{CC}=\mathrm{C} 2(\mathrm{C}=1)))) \mathrm{C}$

$\mathrm{O}=\mathrm{C}(\mathrm{O}) \mathrm{CC} 2(=\mathrm{NC}=1(\mathrm{C}(=\mathrm{CC}=\mathrm{CC}=1) \mathrm{C}=\mathrm{C} 2 \mathrm{C}))$

$\mathrm{O}=\mathrm{C}(\mathrm{O}) \mathrm{CCC}=1(\mathrm{C}=2(\mathrm{C}(\mathrm{C}=\mathrm{NC}=1)=\mathrm{CC}=\mathrm{CC}=2))$

$F C 2(=C C 1(=N C(=C(C(=0) O) C=C 1 C=C 2) C))$

$F C=2(C 1(=N C(=C(C=O) O) C=C 1 C=C C=2) C))$

$\mathrm{FC} 2(=\mathrm{CC} 1(=\mathrm{NC}(=\mathrm{CC}(=\mathrm{C} 1 \mathrm{C}=\mathrm{C} 2) \mathrm{C}(=0) 0) \mathrm{C}))$

$\mathrm{O}=\mathrm{C}(\mathrm{O}) \mathrm{C}=1(\mathrm{C}(=\mathrm{NC} 2(=\mathrm{CC}=\mathrm{CC}=\mathrm{C} 2(\mathrm{C}=1))) \mathrm{C})$

$\mathrm{O}=\mathrm{C}(\mathrm{O}) \mathrm{C}=2(\mathrm{C} 1(=\mathrm{NC}(=\mathrm{CC}=\mathrm{C} 1 \mathrm{C}=\mathrm{CC}=2) \mathrm{C}))$

$\mathrm{O}=\mathrm{C}(\mathrm{O}) \mathrm{C} 2(=\mathrm{CC}=1(\mathrm{C}(=\mathrm{NC}(\mathrm{C})=\mathrm{CC}=1) \mathrm{C}=\mathrm{C} 2))$

$\mathrm{O}=\mathrm{C}(\mathrm{O}) \mathrm{C}=1(\mathrm{C}=2(\mathrm{C}(\mathrm{N}=\mathrm{C}(\mathrm{C}=1) \mathrm{C})=\mathrm{CC}=\mathrm{CC}=2))$

$\mathrm{O}=\mathrm{C}(\mathrm{O}) \mathrm{CC} 2(=\mathrm{NC}=1(\mathrm{C}=\mathrm{CC}=\mathrm{CC}=1) \mathrm{C}=\mathrm{C} 2))$

$\mathrm{O}=\mathrm{C}(\mathrm{O}) \mathrm{CC}=1(\mathrm{C}=\mathrm{NC} 2(=\mathrm{CC}=\mathrm{CC}=\mathrm{C} 2(\mathrm{C}=1)))$ 


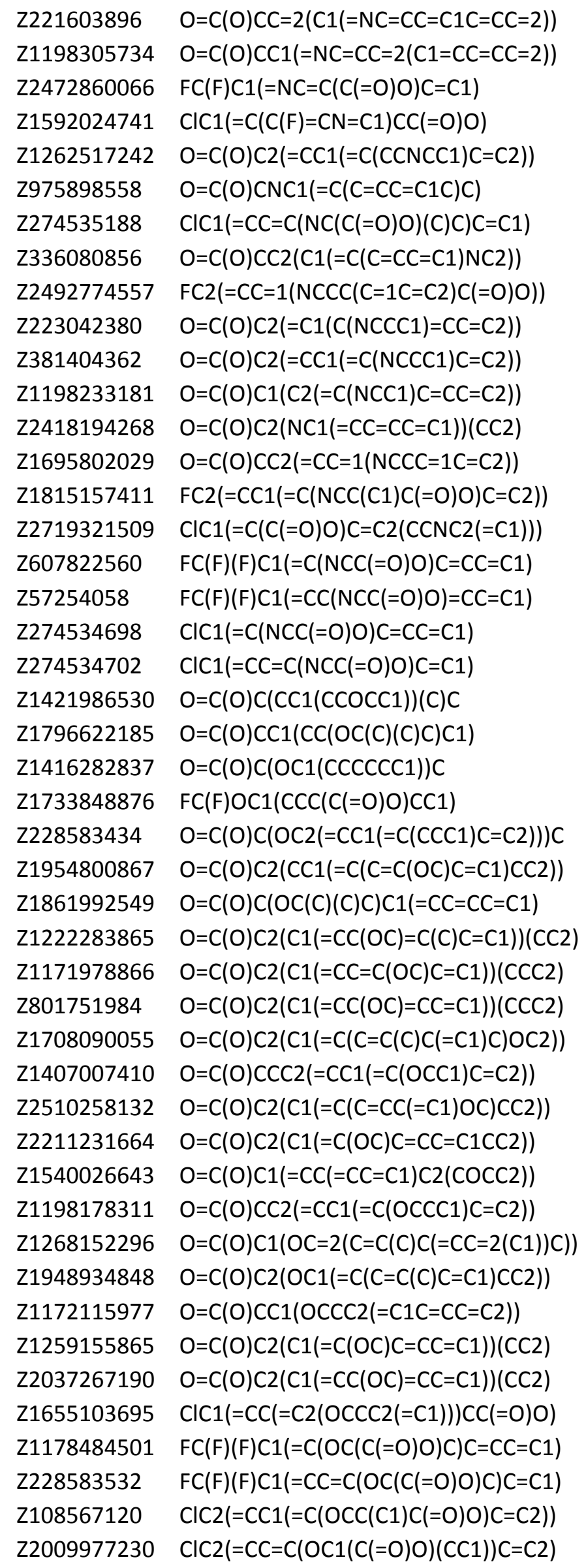


Z1270387220

Z57952782

Z1101435029

Z57047005

Z2217033027

Z220565334

Z1695922825

Z2238934554

Z2235409267

Z1983079578

Z1860991682

Z2470036279

Z2350905873

Z1262557291

Z1664966335

Z1689341669

Z1860991543

Z1359881924

Z65572154

Z104341198

Z228583520

Z228583338

Z65532537

Z90662162

Z94598730

Z1815155515

Z1723549312

Z1741975964

Z1262237311

Z1255523406

Z1171978900

Z89283956

Z1623864140

Z2213893339

Z1416282381

Z1723849111

Z1138836370

Z385445800

Z1171979242

Z2037273275

Z1262514460

Z752942396

Z57316204

Z104341874

Z385445808

Z1171979241
$\mathrm{O}=\mathrm{C}(\mathrm{O}) \mathrm{C} 2(=\mathrm{C} 1(\mathrm{OC}(\mathrm{C}) \mathrm{CC} 1=\mathrm{CC}=\mathrm{C} 2))$

$\mathrm{O}=\mathrm{C}(\mathrm{O}) \mathrm{C} 2(=\mathrm{CC} 1(=\mathrm{C}(\mathrm{OC}(\mathrm{C} 1) \mathrm{C}) \mathrm{C}=\mathrm{C} 2))$

$\mathrm{O}=\mathrm{C}(\mathrm{O}) \mathrm{C} 1(\mathrm{C} 2(=\mathrm{C}(\mathrm{OCC} 1) \mathrm{C}=\mathrm{CC}=\mathrm{C} 2))$

$\mathrm{FC} 1(=\mathrm{CC}=\mathrm{C}(\mathrm{OC}(\mathrm{C}(=\mathrm{O}) \mathrm{O})(\mathrm{C}) \mathrm{C}) \mathrm{C}=\mathrm{C} 1)$

$\mathrm{FC} 2(=\mathrm{CC}=1(\mathrm{OC}(\mathrm{C}(=0) 0) \mathrm{CCC}=1 \mathrm{C}=\mathrm{C} 2))$

$\mathrm{O}=\mathrm{C}(\mathrm{O}) \mathrm{CC} 2(=\mathrm{CC} 1(=\mathrm{C}(\mathrm{OCC} 1) \mathrm{C}=\mathrm{C} 2))$

$\mathrm{FC} 2(=\mathrm{CC} 1(=\mathrm{C}(\mathrm{OCC}(\mathrm{C} 1) \mathrm{C}(=\mathrm{O}) \mathrm{O}) \mathrm{C}=\mathrm{C} 2))$

$\mathrm{O}=\mathrm{C}(\mathrm{O}) \mathrm{C} 1(\mathrm{OC}=2(\mathrm{C}(=\mathrm{CC}=\mathrm{CC}=2(\mathrm{C} 1)) \mathrm{C}))$

$\mathrm{O}=\mathrm{C}(\mathrm{O}) \mathrm{C} 1(\mathrm{OC}=2(\mathrm{C}=\mathrm{CC}=\mathrm{C}(\mathrm{C}=2(\mathrm{C} 1)) \mathrm{C}))$

$\mathrm{FC} 2(=\mathrm{C}(\mathrm{OC} 1(\mathrm{C}(=\mathrm{O}) \mathrm{O})(\mathrm{CC} 1)) \mathrm{C}=\mathrm{CC}=\mathrm{C} 2)$

$\mathrm{FC} 1(=\mathrm{C}(\mathrm{C}=\mathrm{CC}=\mathrm{C} 1) \mathrm{C}(\mathrm{OC})(\mathrm{C}(=\mathrm{O}) \mathrm{O}) \mathrm{C})$

$\mathrm{ClC} 2(=\mathrm{CC} 1(=\mathrm{C}(\mathrm{C}(\mathrm{CC}(=0) \mathrm{O}) \mathrm{OC} 1) \mathrm{C}=\mathrm{C} 2))$

$\mathrm{O}=\mathrm{C}(\mathrm{O}) \mathrm{C} 2(\mathrm{OC} 1(=\mathrm{CC}=\mathrm{CC}=\mathrm{C} 1))(\mathrm{CC} 2)$

$\mathrm{O}=\mathrm{C}(\mathrm{O}) \mathrm{CC} 1(\mathrm{OCC} 2(=\mathrm{C} 1 \mathrm{C}=\mathrm{CC}=\mathrm{C} 2))$

$\mathrm{O}=\mathrm{C}(\mathrm{O}) \mathrm{CC} 2(=\mathrm{CC} 1(=\mathrm{C}(\mathrm{COC} 1) \mathrm{C}=\mathrm{C} 2))$

$\mathrm{ClC} 1(=\mathrm{CC}(=\mathrm{C} 2(\mathrm{OCCC} 2(=\mathrm{C} 1))) \mathrm{C}(=0) 0)$

$\mathrm{ClC} 2(=\mathrm{CC} 1(=\mathrm{C}(\mathrm{OCC} 1 \mathrm{C}(=\mathrm{O}) \mathrm{O}) \mathrm{C}=\mathrm{C} 2))$

$\mathrm{ClC} 1(=\mathrm{CC}(=\mathrm{C}(\mathrm{OC}) \mathrm{C}=\mathrm{C} 1) \mathrm{C}(\mathrm{F})(\mathrm{F}) \mathrm{C}(=\mathrm{O}) \mathrm{O})$

$\mathrm{ClC} 1(=\mathrm{C}(\mathrm{OC}(\mathrm{C}(=\mathrm{O}) \mathrm{O}) \mathrm{C}) \mathrm{C}=\mathrm{CC}(=\mathrm{C} 1) \mathrm{F})$

$\mathrm{ClC2}(=\mathrm{CC} 1(=\mathrm{C}(\mathrm{OC}(\mathrm{C} 1) \mathrm{C}(=\mathrm{O}) \mathrm{O}) \mathrm{C}=\mathrm{C} 2))$

$\mathrm{FC} 1(=\mathrm{C}(\mathrm{F}) \mathrm{C}=\mathrm{CC}(=\mathrm{C} 1) \mathrm{OC}(\mathrm{C}(=\mathrm{O}) \mathrm{O}) \mathrm{C})$

$\mathrm{FC} 1(=\mathrm{CC}(\mathrm{OC}(\mathrm{C}(=\mathrm{O}) \mathrm{O}) \mathrm{C})=\mathrm{CC}=\mathrm{C} 1)$

$\mathrm{FC} 1(=\mathrm{C}(\mathrm{OC}(\mathrm{C}(=\mathrm{O}) \mathrm{O}) \mathrm{C}) \mathrm{C}=\mathrm{CC}=\mathrm{C} 1)$

$\mathrm{FC} 1(=\mathrm{CC}=\mathrm{C}(\mathrm{OC}(\mathrm{C}(=\mathrm{O}) \mathrm{O}) \mathrm{C}) \mathrm{C}=\mathrm{C} 1)$

$\mathrm{FC} 1(=\mathrm{C}(\mathrm{OC}) \mathrm{C}=\mathrm{CC}(=\mathrm{C} 1) \mathrm{CC}(=0) \mathrm{O})$

$\mathrm{FC} 1(=\mathrm{C}(\mathrm{OC}) \mathrm{C}=\mathrm{CC}=\mathrm{C} 1 \mathrm{CC}(=0) \mathrm{O})$

$\mathrm{FC} 1(=\mathrm{CC}(=\mathrm{C}(\mathrm{OC}) \mathrm{C}=\mathrm{C} 1) \mathrm{CC}(=0) \mathrm{O})$

$F C 1(=C(C=C C(=C 1) O C) C C(=0) O)$

$\mathrm{FC} 2(=\mathrm{C} 1(\mathrm{OC}(\mathrm{C}(=\mathrm{O}) \mathrm{O}) \mathrm{CC} 1=\mathrm{CC}=\mathrm{C} 2))$

$\mathrm{FC} 2(=\mathrm{CC} 1(=\mathrm{C}(\mathrm{OC}(\mathrm{C} 1) \mathrm{C}(=\mathrm{O}) \mathrm{O}) \mathrm{C}=\mathrm{C} 2))$

$\mathrm{O}=\mathrm{C}(\mathrm{O}) \mathrm{C} 2(=\mathrm{C}(\mathrm{N}(\mathrm{CC} 1(\mathrm{CC} 1)) \mathrm{C}(=\mathrm{C} 2) \mathrm{C}) \mathrm{C})$

$\mathrm{O}=\mathrm{C}(\mathrm{O}) \mathrm{C} 2(=\mathrm{C}(\mathrm{N}(\mathrm{C} 1(\mathrm{CC} 1)) \mathrm{C}(=\mathrm{C} 2) \mathrm{C}) \mathrm{C})$

$\mathrm{O}=\mathrm{C}(\mathrm{O}) \mathrm{C}=1(\mathrm{~N}(\mathrm{C}=\mathrm{CC}=1) \mathrm{C} 2(\mathrm{CCCC} 2))$

$\mathrm{O}=\mathrm{C}(\mathrm{O}) \mathrm{C} 1(=\mathrm{C}(\mathrm{N}(\mathrm{C}) \mathrm{C}=\mathrm{C} 1) \mathrm{C} 2(\mathrm{CCC} 2))$

$\mathrm{O}=\mathrm{C}(\mathrm{O}) \mathrm{CCC}=2(\mathrm{C} 1(=\mathrm{C}(\mathrm{C}=\mathrm{CC}=\mathrm{C} 1) \mathrm{N}(\mathrm{C}=2) \mathrm{C}))$

$\mathrm{O}=\mathrm{C}(\mathrm{O}) \mathrm{C}(\mathrm{C}=2(\mathrm{C} 1(=\mathrm{C}(\mathrm{C}=\mathrm{CC}=\mathrm{C} 1) \mathrm{N}(\mathrm{C}=2) \mathrm{C}))) \mathrm{C}$

$\mathrm{O}=\mathrm{C}(\mathrm{O}) \operatorname{CCN} 2(\mathrm{C} 1(=\mathrm{C}(\mathrm{C}=\mathrm{C}(\mathrm{C}) \mathrm{C}=\mathrm{C} 1) \mathrm{C}=\mathrm{C} 2))$

$\mathrm{O}=\mathrm{C}(\mathrm{O}) \mathrm{CCN} 2(\mathrm{C} 1(=\mathrm{C}(\mathrm{C}(=\mathrm{CC}=\mathrm{C} 1) \mathrm{C}) \mathrm{C}=\mathrm{C} 2))$

$\mathrm{O}=\mathrm{C}(\mathrm{O}) \mathrm{CC}=2(\mathrm{C} 1(=\mathrm{C}(\mathrm{C}=\mathrm{CC}=\mathrm{C} 1) \mathrm{N}(\mathrm{C}=2) \mathrm{CC}))$

$\mathrm{O}=\mathrm{C}(\mathrm{O}) \mathrm{C}(\mathrm{CN} 2(\mathrm{C} 1(=\mathrm{C}(\mathrm{C}=\mathrm{CC}=\mathrm{C} 1) \mathrm{C}=\mathrm{C} 2))) \mathrm{C}$

$\mathrm{O}=\mathrm{C}(\mathrm{O}) \mathrm{CC}=1(\mathrm{~N}(\mathrm{C}=2(\mathrm{C}=\mathrm{CC}=\mathrm{CC}=2(\mathrm{C}=1))) \mathrm{C})$

$\mathrm{O}=\mathrm{C}(\mathrm{O}) \mathrm{CC}=2(\mathrm{C} 1(=\mathrm{C}(\mathrm{C}=\mathrm{CC}=\mathrm{C} 1) \mathrm{N}(\mathrm{C}=2) \mathrm{C}))$

$\mathrm{O}=\mathrm{C}(\mathrm{O}) \mathrm{CCN} 2(\mathrm{C} 1(=\mathrm{C}(\mathrm{C}=\mathrm{CC}=\mathrm{C} 1) \mathrm{C}=\mathrm{C} 2))$

$\mathrm{O}=\mathrm{C}(\mathrm{O}) \mathrm{CN} 2(\mathrm{C} 1(=\mathrm{C}(\mathrm{C}=\mathrm{CC}=\mathrm{C} 1) \mathrm{C}=\mathrm{C} 2 \mathrm{C}))$

$\mathrm{O}=\mathrm{C}(\mathrm{O}) \mathrm{CN} 2(\mathrm{C} 1(=\mathrm{C}(\mathrm{C}(=\mathrm{CC}=\mathrm{C} 1) \mathrm{C}) \mathrm{C}=\mathrm{C} 2))$

$\mathrm{O}=\mathrm{C}(\mathrm{O}) \mathrm{CN} 2(\mathrm{C} 1(=\mathrm{C}(\mathrm{C}=\mathrm{CC}=\mathrm{C} 1) \mathrm{C}(=\mathrm{C} 2) \mathrm{C}))$ 


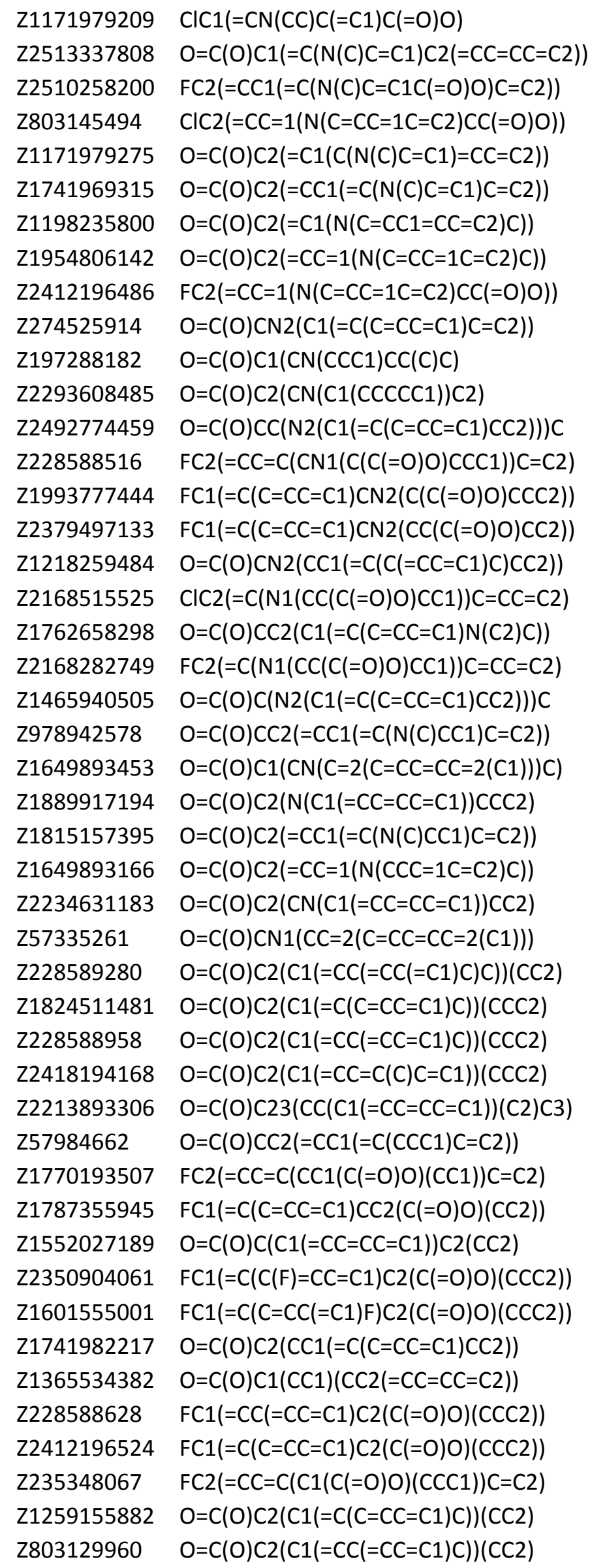




\begin{tabular}{|c|c|}
\hline Z111874776 & $\mathrm{O}=\mathrm{C}(\mathrm{O}) \mathrm{C} 2(\mathrm{C} 1(=\mathrm{CC}=\mathrm{CC}=\mathrm{C} 1))(\mathrm{CCC} 2)$ \\
\hline Z2235683839 & $\mathrm{O}=\mathrm{C}(\mathrm{O}) \mathrm{C} 23(\mathrm{C}(\mathrm{C} 1(=\mathrm{CC}=\mathrm{CC}=\mathrm{C} 1))(\mathrm{C} 2) \mathrm{C} 3)$ \\
\hline Z1198318705 & $\mathrm{FC} 2(=\mathrm{CC} 1(=\mathrm{C}(\mathrm{C}(\mathrm{C}(=0) \mathrm{O}) \mathrm{CC} 1) \mathrm{C}=\mathrm{C} 2))$ \\
\hline Z1259040972 & $\mathrm{FC} 1(=\mathrm{CC}(=\mathrm{CC}=\mathrm{C} 1) \mathrm{CC}(\mathrm{C}(=0) 0) \mathrm{C})$ \\
\hline Z1250132474 & $\mathrm{FC} 1(=\mathrm{C}(\mathrm{C}=\mathrm{CC}=\mathrm{C} 1) \mathrm{CC}(\mathrm{C}(=\mathrm{O}) \mathrm{O}) \mathrm{C})$ \\
\hline Z1259040983 & $\mathrm{FC} 1(=\mathrm{CC}=\mathrm{C}(\mathrm{CC}(\mathrm{C}(=0) 0) \mathrm{C}) \mathrm{C}=\mathrm{C} 1)$ \\
\hline Z316170302 & $\mathrm{ClC} 1(=\mathrm{CC}(=\mathrm{CC}=\mathrm{C} 1) \mathrm{C} 2(\mathrm{C}(=0) \mathrm{O})(\mathrm{CC} 2))$ \\
\hline Z118257516 & $\mathrm{ClC} 2(=\mathrm{CC}=\mathrm{C}(\mathrm{C} 1(\mathrm{C}(=\mathrm{O}) \mathrm{O})(\mathrm{CC} 1)) \mathrm{C}=\mathrm{C} 2)$ \\
\hline Z1270326280 & $\mathrm{FC} 1(=\mathrm{CC}(=\mathrm{CC}=\mathrm{C} 1) \mathrm{C} 2(\mathrm{C}(=0) \mathrm{O})(\mathrm{CC} 2))$ \\
\hline Z1259341101 & $\mathrm{FC} 1(=\mathrm{C}(\mathrm{C}=\mathrm{CC}=\mathrm{C} 1) \mathrm{C} 2(\mathrm{C}(=0) 0)(\mathrm{CC} 2))$ \\
\hline Z228588556 & $\mathrm{FC} 2(=\mathrm{CC}=\mathrm{C}(\mathrm{C} 1(\mathrm{C}(=\mathrm{O}) \mathrm{O})(\mathrm{CC} 1)) \mathrm{C}=\mathrm{C} 2)$ \\
\hline Z199056488 & $\mathrm{FC}(\mathrm{F})(\mathrm{F}) \mathrm{C} 1(=\mathrm{CC}(=\mathrm{CC}=\mathrm{C} 1) \mathrm{CC}(=0) 0)$ \\
\hline Z1814381834 & $\mathrm{FC}(\mathrm{F}) \mathrm{C} 1(=\mathrm{CC}(=\mathrm{CC}=\mathrm{C} 1) \mathrm{CC}(=0) 0)$ \\
\hline Z367452204 & $\mathrm{FC} 1(=\mathrm{C}(\mathrm{F}) \mathrm{C}=\mathrm{CC}(=\mathrm{C} 1) \mathrm{CCC}(=0) 0)$ \\
\hline Z992717042 & $\mathrm{FC} 1(=\mathrm{C}(\mathrm{F}) \mathrm{C}=\mathrm{CC}=\mathrm{C} 1 \mathrm{CCC}(=\mathrm{O}) \mathrm{O})$ \\
\hline Z803145538 & $\mathrm{FC} 1(=\mathrm{C}(\mathrm{C}=\mathrm{C}(\mathrm{F}) \mathrm{C}=\mathrm{C} 1) \mathrm{CCC}(=0) 0)$ \\
\hline Z1492781331 & $\mathrm{FC} 1(=\mathrm{C}(\mathrm{C}=\mathrm{CC}(=\mathrm{C} 1) \mathrm{F}) \mathrm{CCC}(=0) \mathrm{O})$ \\
\hline Z1172068239 & $\mathrm{FC} 1(=\mathrm{C}(\mathrm{C}(\mathrm{F})=\mathrm{CC}=\mathrm{C} 1) \mathrm{CCC}(=0) 0)$ \\
\hline Z1263529817 & $\mathrm{FC} 1(=\mathrm{C}(\mathrm{C}=\mathrm{CC}(=\mathrm{C} 1) \mathrm{F}) \mathrm{C}(\mathrm{C}(=\mathrm{O}) \mathrm{O}) \mathrm{C})$ \\
\hline Z1558209956 & $\mathrm{FC} 1(=\mathrm{C}(\mathrm{C}(\mathrm{F})=\mathrm{CC}=\mathrm{C} 1) \mathrm{C}(\mathrm{C}(=\mathrm{O}) \mathrm{O}) \mathrm{C})$ \\
\hline Z2235790638 & $\mathrm{FC} 1(=\mathrm{C}(\mathrm{C}=\mathrm{C}(\mathrm{F}) \mathrm{C}(=\mathrm{C} 1) \mathrm{C}) \mathrm{CC}(=0) 0)$ \\
\hline Z1259040982 & $\mathrm{ClC} 1(=\mathrm{CC}(=\mathrm{CC}=\mathrm{C} 1) \mathrm{C}(\mathrm{F})(\mathrm{F}) \mathrm{C}(=\mathrm{O}) \mathrm{O})$ \\
\hline Z1741978268 & $\mathrm{ClC} 1(=\mathrm{C}(\mathrm{F}) \mathrm{C}=\mathrm{C}(\mathrm{CC}(=\mathrm{O}) \mathrm{O}) \mathrm{C}=\mathrm{C} 1)$ \\
\hline Z1741959672 & $\mathrm{ClC} 1(=\mathrm{C}(\mathrm{F}) \mathrm{C}(=\mathrm{CC}=\mathrm{C} 1) \mathrm{CC}(=0) 0)$ \\
\hline
\end{tabular}


Table S2. X-ray structure determination: PDB codes, data collection and refinement

\begin{tabular}{|c|c|c|c|c|c|c|c|}
\hline & $20 \mathrm{i}$ & 26 & 7 & 5 & 10 & 8 & 6 \\
\hline PDB ID code & 6YXI & 6YSK & 6YUW & 6YUY & 6YV0 & 6YV2 & 6YV4 \\
\hline Ligand code & PZ8 & PJK & PQZ & $\mathrm{PQH}$ & PQT & PUE & PQK \\
\hline \multicolumn{8}{|l|}{ Data collection } \\
\hline $\begin{array}{l}\text { X-ray source } \\
\text { (Diamond) }\end{array}$ & $\mathrm{I} 04$ & I03 & $\mathrm{I} 24$ & $\mathrm{I} 24$ & $\mathrm{I} 24$ & $\mathrm{I} 24$ & $\mathrm{I} 24$ \\
\hline Wavelength $(\AA)$ & 0.9795 & 0.9762 & 0.9686 & 0.9686 & 0.9686 & 0.9686 & 0.9686 \\
\hline Space group & $\mathrm{P} 2_{1} 2_{1} 2_{1}$ & $\mathrm{P} 2{ }_{1} 2_{1} 2_{1}$ & $\mathrm{P} 2{ }_{1} 2_{1} 2_{1}$ & $\mathrm{P} 2_{1} 2_{1} 2_{1}$ & $\mathrm{P} 2_{1} 2_{1} 2_{1}$ & $\mathrm{P} 2_{1} 2_{1} 2_{1}$ & $\mathrm{P} 2_{1} 2_{1} 2_{1}$ \\
\hline \multicolumn{8}{|l|}{ Cell dimensions } \\
\hline a, b, c $(\AA)$ & $59.52,72.16,77.93$ & $59.94,71.90,78.41$ & $\begin{array}{c}59.40,73.26 \\
78.40\end{array}$ & $\begin{array}{c}59.40,73.08 \\
78.58\end{array}$ & $\begin{array}{c}59.44,73.22 \\
78.67\end{array}$ & $\begin{array}{c}59.30,73.02 \\
79.46\end{array}$ & $\begin{array}{c}59.24,73.46 \\
79.38\end{array}$ \\
\hline$\alpha, \beta, \gamma\left({ }^{\circ}\right)$ & $90,90,90$ & $90,90,90$ & $90,90,90$ & $90,90,90$ & $90,90,90$ & $90,90,90$ & $90,90,90$ \\
\hline Resolution $(\AA)$ & $\begin{array}{c}59.52-1.34(1.36- \\
1.34)\end{array}$ & $\begin{array}{c}59.9-1.21(1.24- \\
1.21)\end{array}$ & $\begin{array}{c}78.4-1.68(1.71- \\
1.68)\end{array}$ & $\begin{array}{c}73.15-1.68(1.71- \\
1.68)\end{array}$ & $\begin{array}{c}59.5-1.97(2.0- \\
1.97)\end{array}$ & $\begin{array}{c}79.51-1.89(1.92 \\
-1.89)\end{array}$ & $\begin{array}{c}73.45-1.72(1.75- \\
1.72)\end{array}$ \\
\hline Rmerge & $0.054(1.147)$ & $0.072(1.62)$ & $0.097(1.510)$ & $0.088(1.666)$ & $0.115(0.860)$ & $0.127(0.352)$ & $0.095(1.576)$ \\
\hline $\mathrm{I} / \sigma(\mathrm{I})$ & $17.6(1)$ & $15.8(1.16)$ & $12.5(0.7)$ & $13.8(1.1)$ & $8.9(1.8)$ & $11.5(6.7)$ & $13.4(1.2)$ \\
\hline CC $1 / 2$ & $1.000(0.555)$ & $1.00(0.675)$ & $1.0(0.8)$ & $1.0(0.8)$ & $1.0(0.9)$ & $1.0(1.0)$ & $1.0(0.9)$ \\
\hline Completeness (\%) & $99.97(99.54)$ & 99.98(99.89) & $100.0(100.0)$ & $100.0(99.4)$ & $99.9(99.4)$ & $99.9(98.4)$ & $100.0(99.6)$ \\
\hline Redundancy & $12.1(6.3)$ & $13.7(12.6)$ & $12.2(12.8)$ & $12.2(12.8)$ & $6.5(6.5)$ & $11.9(6.8)$ & $12.3(12.9)$ \\
\hline \multicolumn{8}{|l|}{ Refinement } \\
\hline Resolution $(\AA)$ & $\begin{array}{c}52.95-1.34(1.36- \\
1.34)\end{array}$ & $\begin{array}{c}39.2-1.21(1.24- \\
1.21)\end{array}$ & $\begin{array}{c}47.34-1.94(2.01- \\
1.94)\end{array}$ & $\begin{array}{c}36.54-2.00(2.07- \\
2.0)\end{array}$ & $\begin{aligned} 36.61 & -2.00(2.07 \\
& -2.0)\end{aligned}$ & $\begin{array}{c}36.51-2.10(2.18- \\
2.10)\end{array}$ & $\begin{array}{c}47.48-2.0(2.07- \\
2.0)\end{array}$ \\
\hline
\end{tabular}




\begin{tabular}{|c|c|c|c|c|c|c|c|}
\hline No. reflections & $75868(2742)$ & $103754(10237)$ & $25902(2571)$ & $23627(2313)$ & $23706(2306)$ & 19997 (2016) & $23895(2328)$ \\
\hline Rwork / Rfree & $0.159 / 0.185$ & $0.195 / 0.210$ & $0.193 / 0.227$ & $0.194 / 0.231$ & $0.211 / 0.234$ & $0.213 / 0.226$ & $0.181 / 0.233$ \\
\hline \multicolumn{8}{|l|}{ No. atoms } \\
\hline Total & 3196 & 3122 & 3087 & 3106 & 3059 & 3063 & 3103 \\
\hline Protein & 2920 & 2910 & 2899 & 2865 & 2900 & 2901 & 2911 \\
\hline Ligand/other & $17 / 61$ & $19 / 70$ & $14 / 24$ & $13 / 104$ & $15 / 35$ & $14 / 41$ & $13 / 44$ \\
\hline Water & 198 & 123 & 150 & 117 & 109 & 107 & 135 \\
\hline \multicolumn{8}{|l|}{ B-factors $\left(\AA^{2}\right)$} \\
\hline All atoms & 29.51 & 26.54 & 37.9 & 42.77 & 47.18 & 47.81 & 45.91 \\
\hline Protein & 28.37 & 25.39 & 37.46 & 41.28 & 46.95 & 47.48 & 45.34 \\
\hline Ligand/inside pocket & 26.57 & 55.14 & 43.86 & $47.94 / 50.71$ & 52.7 & 38.29 & 40.49 \\
\hline Solvent & 39.31 & 33.06 & 41.45 & 45.35 & 48.97 & 49.34 & 49.07 \\
\hline \multicolumn{8}{|l|}{ R.m.s. deviations } \\
\hline Bond lengths $(\AA)$ & 0.006 & 0.011 & 0.01 & 0.009 & 0.005 & 0.003 & 0.011 \\
\hline Bond angles $\left({ }^{\circ}\right)$ & 0.79 & 1.19 & 1 & 1.21 & 0.71 & 0.65 & 1.38 \\
\hline
\end{tabular}


Figure S1: Weakly active pyrrole $\mathbf{S} 1$ and inactive pyrrolidine $\mathbf{S} 2$ present in the acid fragment library.

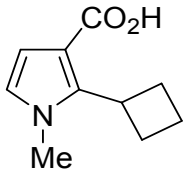

S1

$$
\mathrm{IC}_{50} 60 \mu \mathrm{M}(\mathrm{n}=1)
$$$$
\mathrm{IC}_{50}>100 \mu \mathrm{M}(\mathrm{n}=3)^{\mathrm{a}}
$$

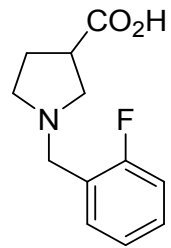

S2

$I C_{50} \gg 100 \mu \mathrm{M}(\mathrm{n}=4)^{\mathrm{b}}$

a $25-45 \%$ I @ $100 \mu \mathrm{M}$.

b $<20 \%$ I@ $100 \mu \mathrm{M}$. 
Figure S2: Inhibition of Notum activity of additional pyrroles and pyrrolidines. ${ }^{a}$

Additional pyrroles (S3-S7) and pyrrolidines (S8-S11) were prepared by the general methods as described and data presented here for a more complete analysis of the SARs.

A: Pyrrole SAR

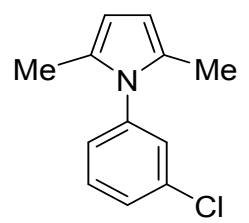

S3

$\mathrm{IC}_{50} 1.8 \pm 0.33 \mu \mathrm{M}$

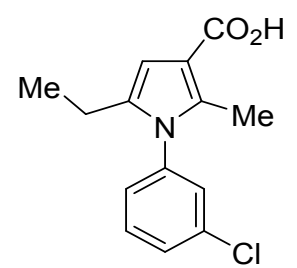

S4

$I_{50} 1.6 \pm 0.26 \mu \mathrm{M}$<smiles>Cc1cc(CC(=O)O)c(C)n1-c1ccc(Cl)cc1</smiles>

S5

$\mathrm{IC}_{50} 8.5 \pm 2.2 \mu \mathrm{M}$<smiles>Cc1cc(C(=O)O)c(C)n1-c1cncc(Cl)c1</smiles>

S6

$I_{50} 11 \pm 1.7 \mu \mathrm{M}$
B: Pyrrolidine SAR

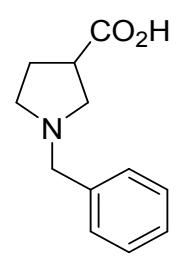

S8

$I_{50} \gg 100 \mu \mathrm{M}^{\mathrm{b}}$

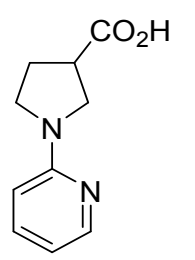

S9

$I C_{50} \gg>100 \mu M^{b}$

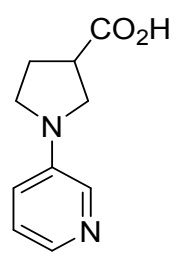

S10

$\mathrm{IC}_{50}>>100 \mu \mathrm{M}^{\mathrm{b}}$

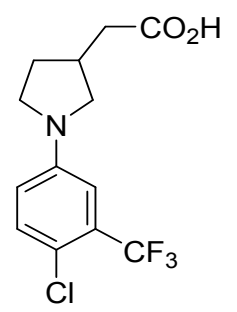

S11

$\mathrm{IC}_{50} 1.9 \pm 0.3 \mu \mathrm{M}$ 


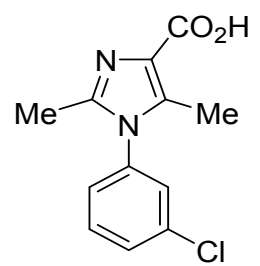

S7

$\mathrm{IC}_{50} 14 \pm 2.3 \mu \mathrm{M}$

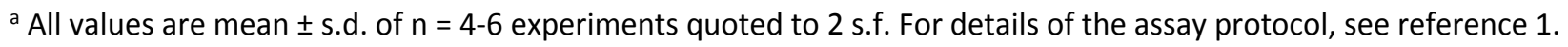
${ }^{b}<20 \%$ I@ $100 \mu \mathrm{M}$. 
Figure S3: Spectroscopic and analytical data for (S)-1-(4-chloro-3-(trifluoromethyl)phenyl)pyrrolidine-3carboxylic acid ((S)-26)<smiles>O=C(O)[C@H]1CCN(c2ccc(Cl)c(C(F)(F)F)c2)C1</smiles>

26: 35

$\mathrm{C}_{12} \mathrm{H}_{11} \mathrm{ClF}_{3} \mathrm{NO}_{2} ; \mathrm{mw} 293.67$

A: ${ }^{1} \mathrm{H}$ NMR $\left(700 \mathrm{MHz}, \mathrm{DMSO}-d_{6}\right)$ of $\mathbf{2 6}$ :

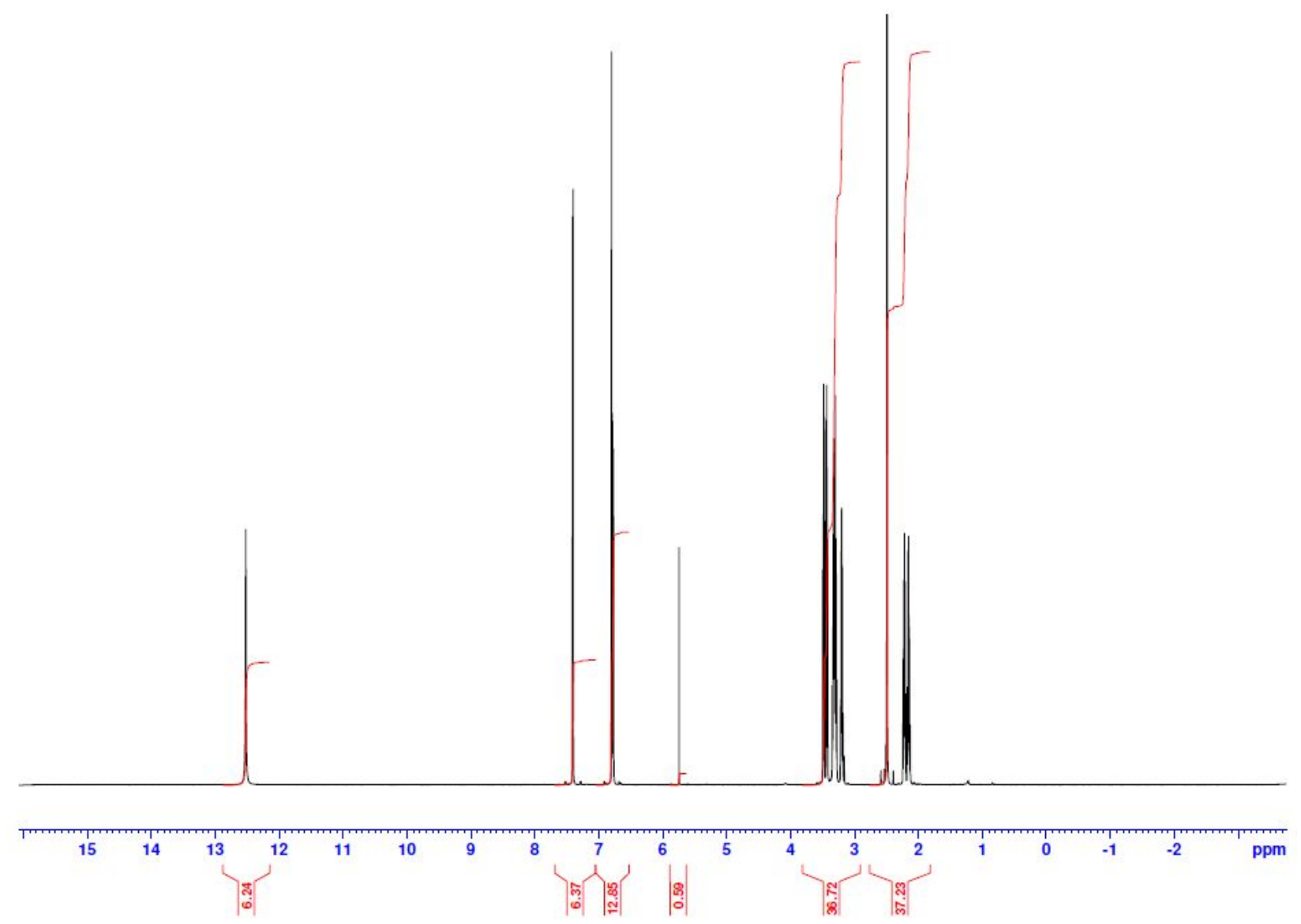


B: ${ }^{13} \mathrm{C}$ NMR (176 MHz, DMSO- $d_{6}$ ) of 26:
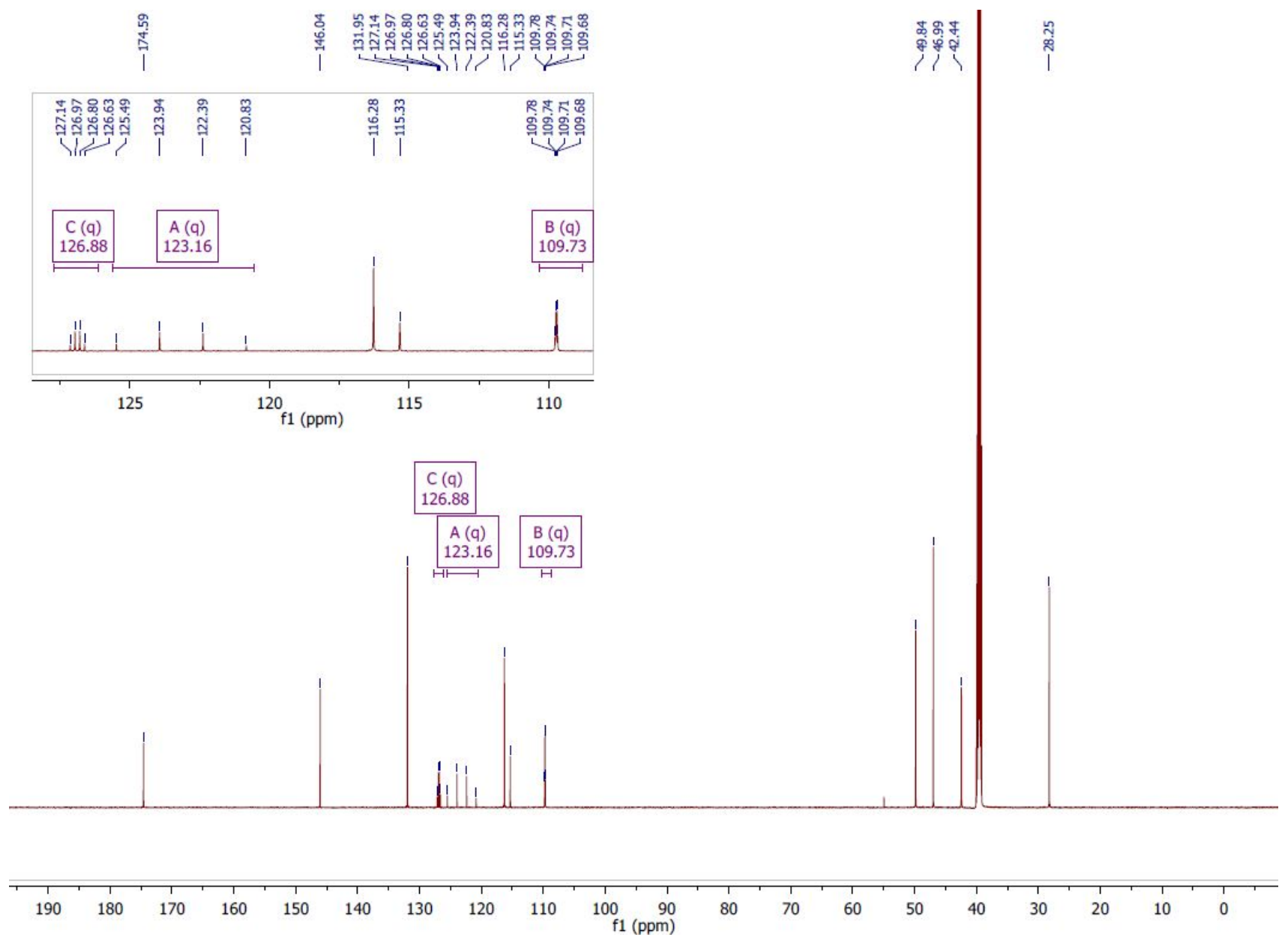

C: LCMS of 26:

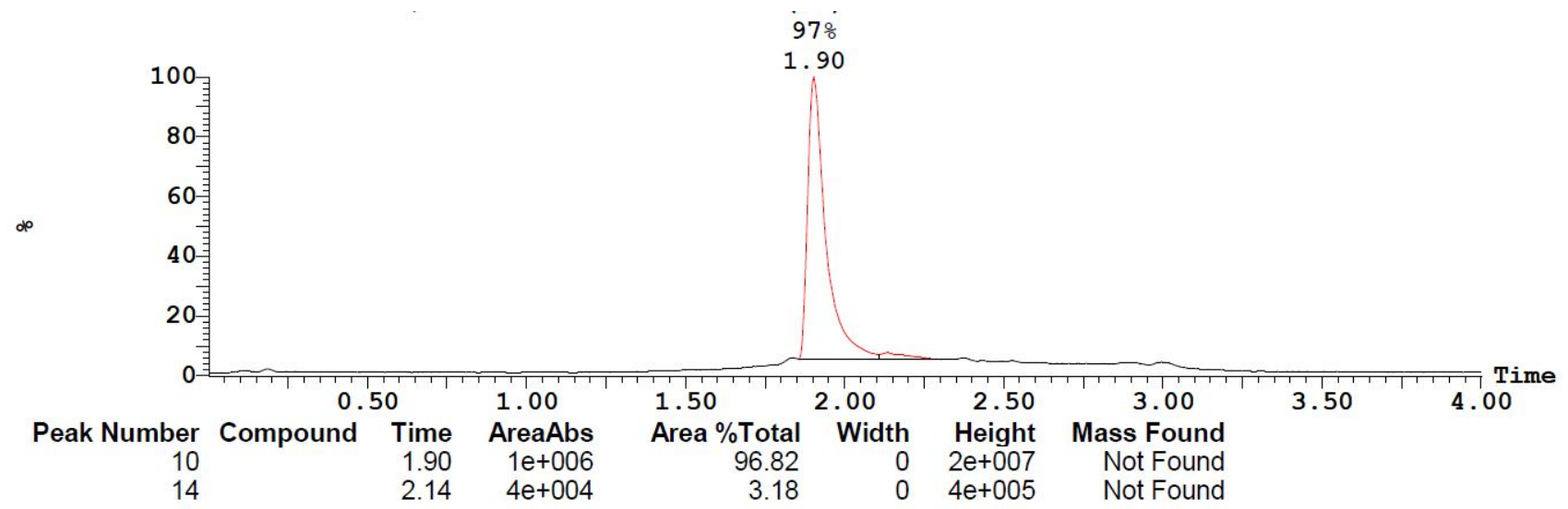

\section{Peak ID Compound Time Mass Found}

$\begin{array}{ccc}10 & 1.90 \quad \text { Not Found } \\ \text { (Time: } 1.90) & \text { Combine }(398: 420-(366: 376+442: 452) \text { ) }\end{array}$

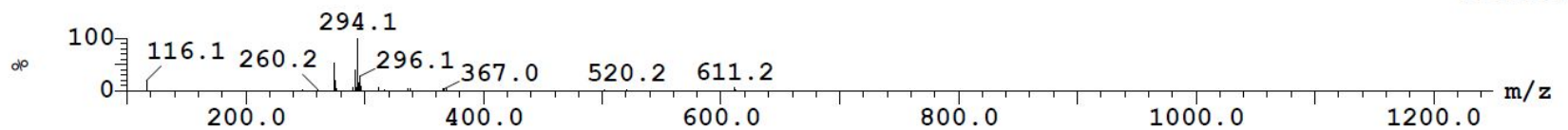

294.1 
D: Chiral analysis of racemic $\mathbf{2 5 q}$ :

Our sample of 'racemic' 25q used in the chiral SFC analysis was created from combination of two authentic samples of (S)-26 and (R)-27 prepared from the corresponding chiral esters, methyl $(S)$ - and $(R)$-pyrrolidine-3carboxylate (36), as described in Scheme 2. Hence, this is why the chromatogram shows a slight bias towards Peak 2.

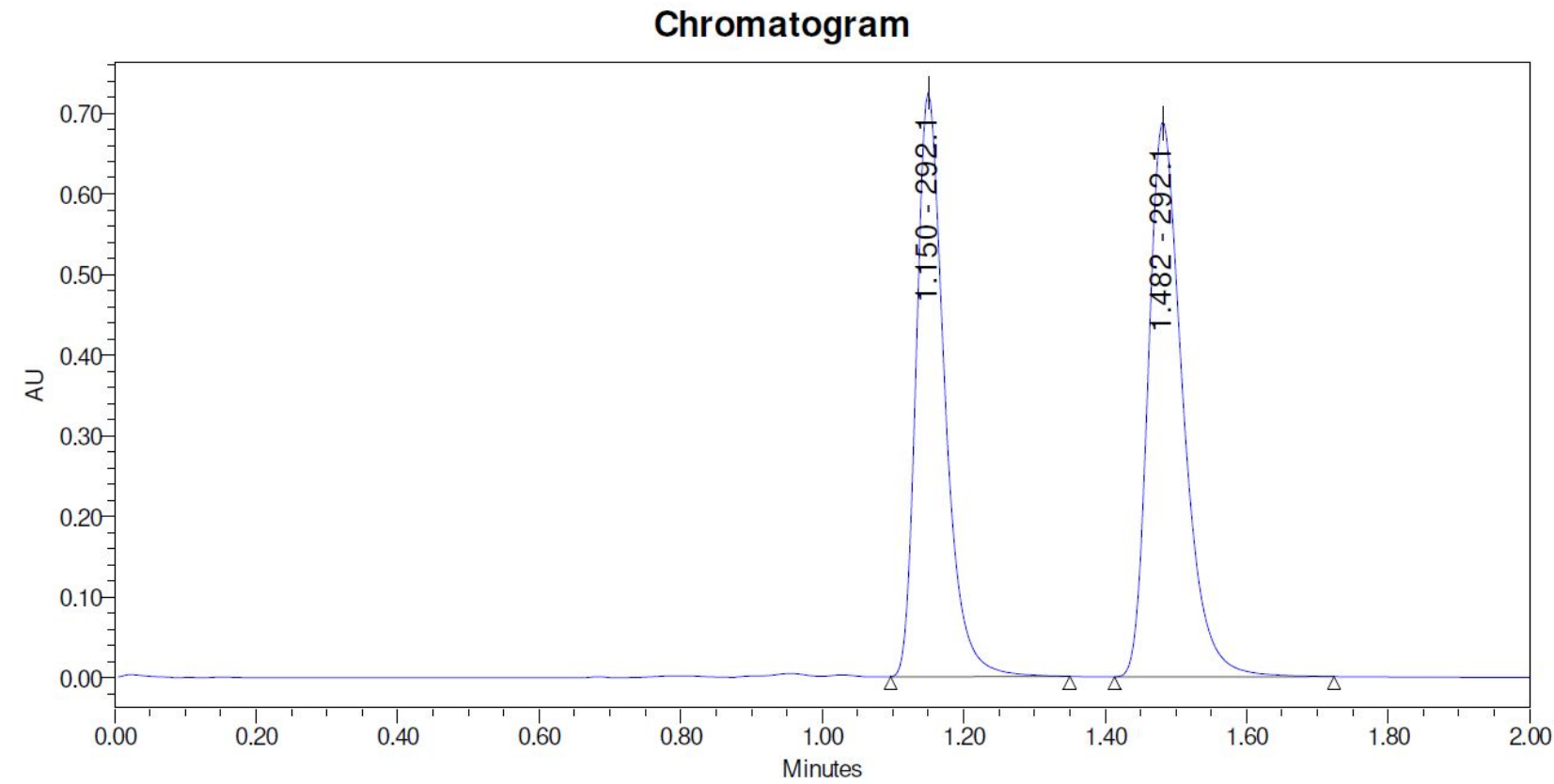

\section{Peak Results}

\begin{tabular}{|l|r|r|r|r|}
\hline & $\begin{array}{c}\text { Retention } \\
\text { Time } \\
(\mathrm{min})\end{array}$ & $\begin{array}{c}\text { Area } \\
\left(\mu \mathrm{V}^{*} \text { sec }\right)\end{array}$ & $\%$ Area & Width @ 50\% \\
\hline 1 & 1.15 & 2014032 & 46.3 & 0.04133 \\
\hline 2 & 1.48 & 2332469 & 53.7 & 0.05078 \\
\hline
\end{tabular}

\begin{tabular}{|l|l|}
\hline Column Details & Amy-C $(4.6 \mathrm{~mm} \times 250 \mathrm{~mm}, 5 \mathrm{um})$ \\
\hline Column Temperature & $40^{\circ} \mathrm{C}$ \\
\hline Flow Rate & $4 \mathrm{~mL} / \mathrm{min}$ \\
\hline Detector Wavelength & $210-400 \mathrm{~nm}$ \\
\hline Injection Volume & $1.0 \mathrm{uL}$ \\
\hline BPR & $125 \mathrm{BarG}$ \\
\hline Isocratic Conditions & $30: 70 \mathrm{EtOH}: \mathrm{CO} 2(0.2 \% \mathrm{v} / \mathrm{v} \mathrm{NH} 3)$ \\
\hline
\end{tabular}


E: Chemical Purity of (S)-26:

PDA Chromatogram

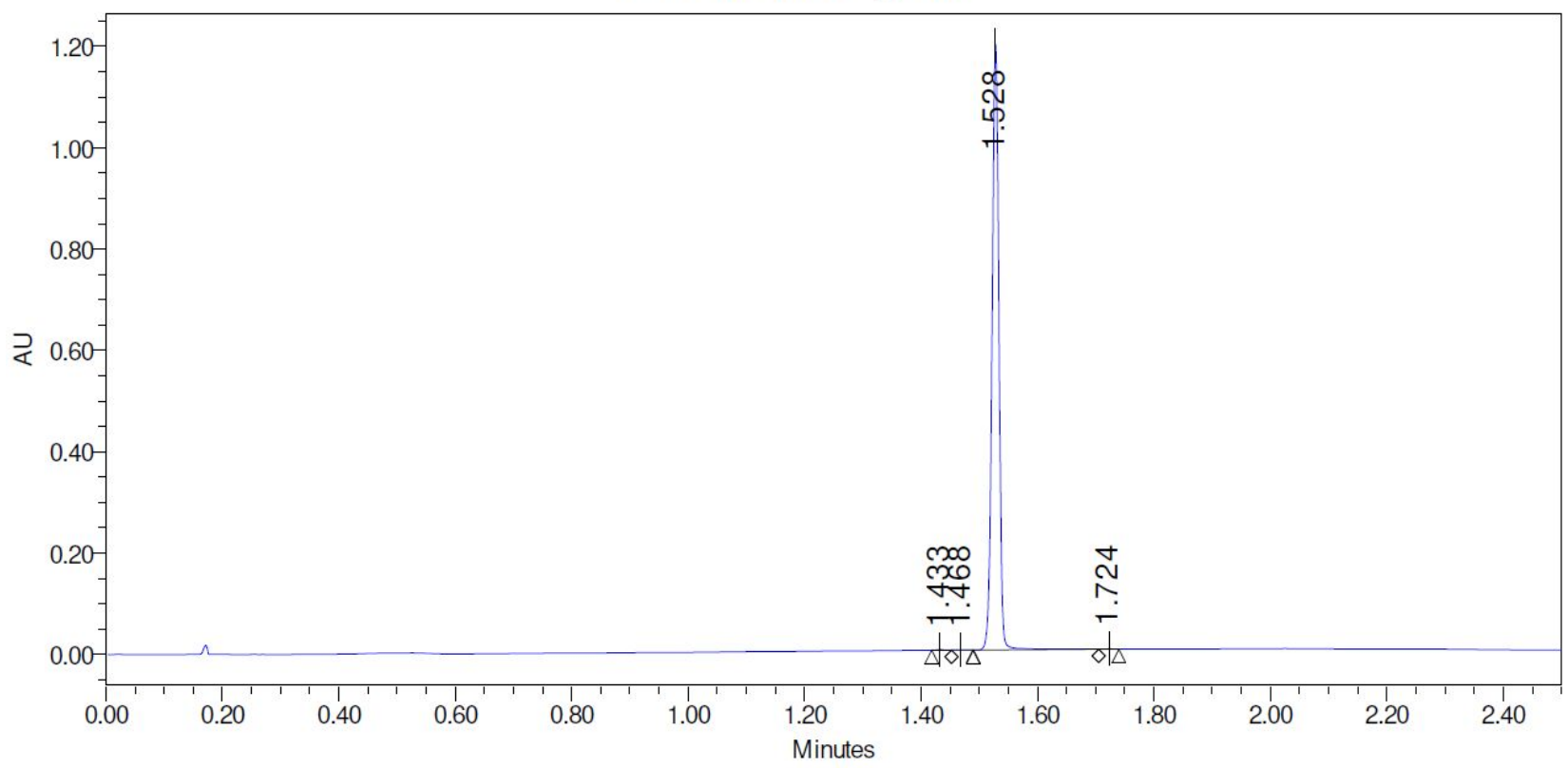

PDA Peak Results

\begin{tabular}{|r|r|r|r|r|}
\hline & $\begin{array}{c}\text { Retention } \\
\text { Time } \\
(\mathrm{min})\end{array}$ & $\begin{array}{c}\text { Area } \\
\left(\mu \mathrm{V}^{*} \mathrm{sec}\right)\end{array}$ & $\%$ Area & $\begin{array}{c}\text { Width } \\
(\mathrm{sec})\end{array}$ \\
\hline 1 & 1.43 & 1011 & 0.10 & 2.050 \\
\hline 2 & 1.47 & 431 & 0.04 & 2.200 \\
\hline 3 & 1.53 & 975325 & 99.78 & 12.900 \\
\hline 4 & 1.72 & 753 & 0.08 & 2.100 \\
\hline
\end{tabular}

\begin{tabular}{|l|l|}
\hline Column Details & Acquity $\mathrm{BEH} \mathrm{C} 18(50 \times 2.1 \mathrm{~mm}, 1.7 \mathrm{um})$ \\
\hline Column Temperature & $60^{\circ} \mathrm{C}$ \\
\hline Flow Rate & $1.0 \mathrm{~mL} /$ minute \\
\hline Detector Wavelength & $220-300 \mathrm{~nm}$ \\
\hline Injection Volume & $1.0 \mathrm{uL}$ \\
\hline Mobile Phase A & Water $(0.1 \% \mathrm{v} / \mathrm{v}$ TFA $)$ \\
\hline Mobile Phase B & MeCN \\
\hline
\end{tabular}

\begin{tabular}{|l|l|l|l|}
\hline Gradient Profile & Time(mins) & $\% \mathrm{~A}$ & $\% \mathrm{~B}$ \\
\hline & 0 & 98 & 2 \\
\hline 2 & 2 & 98 \\
\cline { 2 - 4 } & 2.02 & 0 & 100 \\
\hline 2.52 & 0 & 100 \\
\hline 2.54 & 98 & 2 \\
\hline 4.00 & 98 & 2 \\
\hline
\end{tabular}


F: Chiral Purity of (S)-26:

\section{Chromatogram}

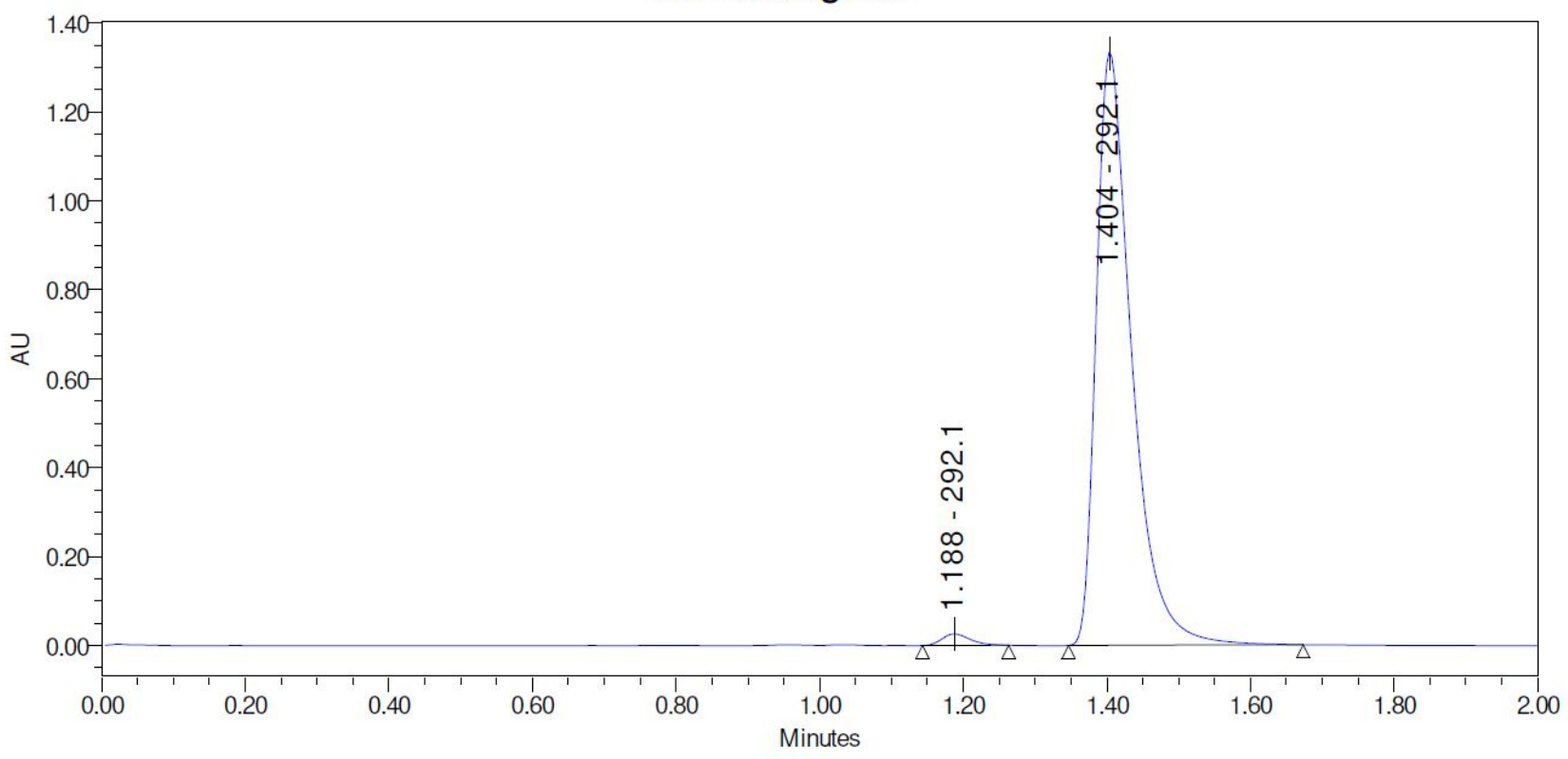

Peak Results

\begin{tabular}{|r|r|r|r|r|}
\hline & $\begin{array}{c}\text { Retention } \\
\text { Time } \\
(\mathrm{min})\end{array}$ & $\begin{array}{c}\text { Area } \\
\left(\mu \mathrm{V}^{*} \sec \right)\end{array}$ & $\%$ Area & Width @ 50\% \\
\hline 1 & 1.19 & 70856 & 1.5 & 0.04204 \\
\hline 2 & 1.40 & 4572806 & 98.5 & 0.05037 \\
\hline
\end{tabular}

\begin{tabular}{|l|l|}
\hline Column Details & Amy-C $(4.6 \mathrm{~mm} \times 250 \mathrm{~mm}, 5 \mathrm{um})$ \\
\hline Column Temperature & $40^{\circ} \mathrm{C}$ \\
\hline Flow Rate & $4 \mathrm{~mL} / \mathrm{min}$ \\
\hline Detector Wavelength & $210-400 \mathrm{~nm}$ \\
\hline Injection Volume & $1.0 \mathrm{uL}$ \\
\hline BPR & $125 \mathrm{BarG}$ \\
\hline Isocratic Conditions & $30: 70 \mathrm{EtOH}: \mathrm{CO} 2(0.2 \% \mathrm{v} / \mathrm{v} \mathrm{NH} 3)$ \\
\hline
\end{tabular}


G: Chemical Purity of $(R)-27$ :

PDA Chromatogram

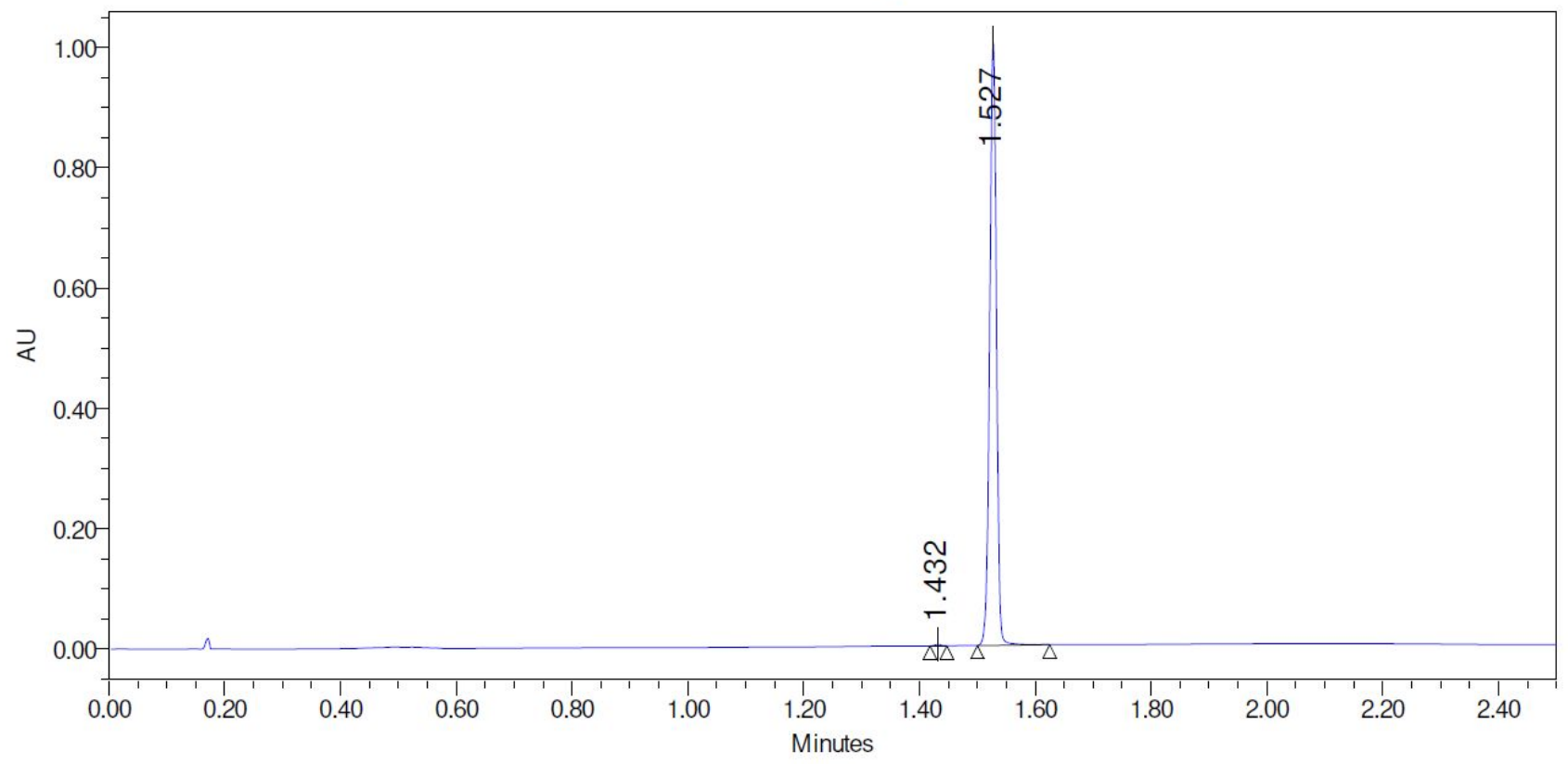

PDA Peak Results

\begin{tabular}{|r|r|r|r|r|}
\hline & $\begin{array}{c}\text { Retention } \\
\text { Time } \\
(\mathrm{min})\end{array}$ & $\begin{array}{c}\text { Area } \\
\left(\mu \mathrm{V}^{*} \mathrm{sec}\right)\end{array}$ & $\%$ Area & $\begin{array}{c}\text { Width } \\
(\mathrm{sec})\end{array}$ \\
\hline 1 & 1.43 & 1614 & 0.20 & 1.750 \\
\hline 2 & 1.53 & 812166 & 99.80 & 7.500 \\
\hline
\end{tabular}

\begin{tabular}{|l|l|}
\hline Column Details & Acquity BEH C18 $(50 \times 2.1 \mathrm{~mm}, 1.7 \mathrm{um})$ \\
\hline Column Temperature & $60^{\circ} \mathrm{C}$ \\
\hline Flow Rate & $1.0 \mathrm{~mL} /$ minute \\
\hline Detector Wavelength & $220-300 \mathrm{~nm}$ \\
\hline Injection Volume & $1.0 \mathrm{uL}$ \\
\hline Mobile Phase A & Water $(0.1 \% \mathrm{v} / \mathrm{v}$ TFA $)$ \\
\hline Mobile Phase B & MeCN \\
\hline
\end{tabular}

\begin{tabular}{|l|l|l|l|}
\hline Gradient Profile & Time(mins) & $\% \mathrm{~A}$ & $\% \mathrm{~B}$ \\
\hline & 0 & 98 & 2 \\
\cline { 2 - 4 } & 2 & 2 & 98 \\
\hline 2.02 & 0 & 100 \\
\hline 2.52 & 0 & 100 \\
\hline 2.54 & 98 & 2 \\
\hline 4.00 & 98 & 2 \\
\hline
\end{tabular}


H: Chiral Purity of $(R)-27$ :

\section{Chromatogram}

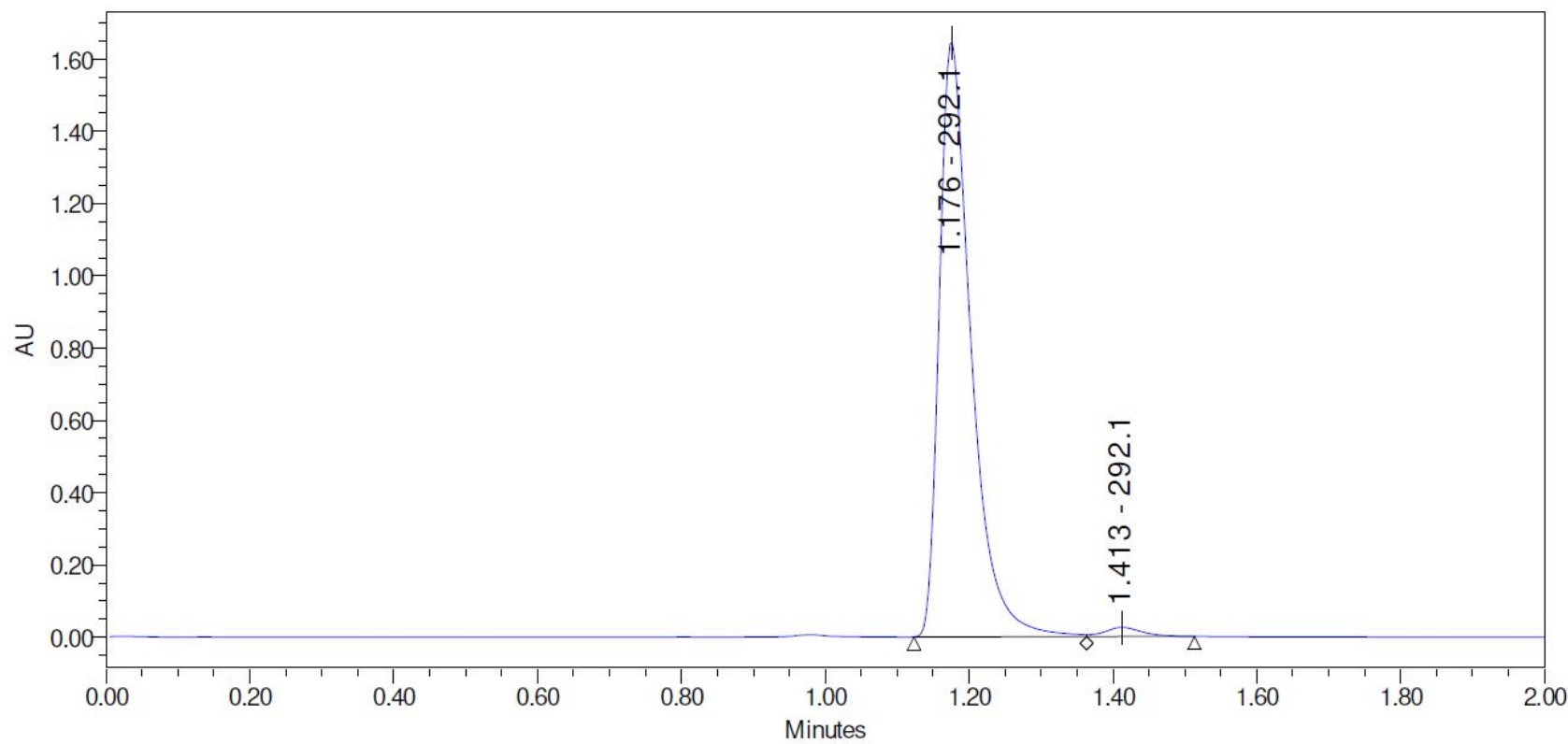

Peak Results

\begin{tabular}{|r|r|r|r|r|}
\hline & $\begin{array}{c}\text { Retention } \\
\text { Time } \\
(\min )\end{array}$ & $\begin{array}{c}\text { Area } \\
\left(\mu \mathrm{V}^{*} \text { sec }\right)\end{array}$ & $\%$ Area & Width @ 50\% \\
\hline 1 & 1.18 & 5070640 & 98.2 & 0.04518 \\
\hline 2 & 1.41 & 92206 & 1.8 & 0.05388 \\
\hline
\end{tabular}

\begin{tabular}{|l|l|}
\hline Column Details & Amy-C $(4.6 \mathrm{~mm} \times 250 \mathrm{~mm}, 5 \mathrm{um})$ \\
\hline Column Temperature & $40^{\circ} \mathrm{C}$ \\
\hline Flow Rate & $4 \mathrm{~mL} / \mathrm{min}$ \\
\hline Detector Wavelength & $210-400 \mathrm{~nm}$ \\
\hline Injection Volume & $1.0 \mathrm{uL}$ \\
\hline BPR & $125 \mathrm{BarG}$ \\
\hline Isocratic Conditions & $30: 70 \mathrm{EtOH}: \mathrm{CO} 2(0.2 \% \mathrm{v} / \mathrm{v} \mathrm{NH} 3)$ \\
\hline
\end{tabular}


Figure S4: ADME data for compounds 20z, 26, $28 \mathrm{e}$ and $\mathbf{3 0 .}$

A. Aqueous solubility at $\mathrm{pH} 7.4$ :

\begin{tabular}{|c|c|c|}
\hline \multirow[b]{2}{*}{ Compound } & \multicolumn{2}{|c|}{ Solubility at $\mathrm{pH} 7.4$} \\
\hline & $\begin{array}{l}\text { Avg. Sol } \\
(\mu \mathrm{g} / \mathrm{mL})\end{array}$ & SD \\
\hline $20 z$ & 13.97 & 0.93 \\
\hline 26 & $>145$ & \\
\hline $28 \mathrm{e}$ & 6.92 & 0.19 \\
\hline 30 & 22.82 & 0.21 \\
\hline Albendazole & 0.65 & 0.14 \\
\hline Flurbiprofen & 74.59 & 1.04 \\
\hline
\end{tabular}

Criteria for classification of the compounds (solubility):

\begin{tabular}{|c|c|}
\hline Result of Solubility $(\mu \mathrm{g} / \mathrm{mL})$ & Range \\
\hline$<10 \mu \mathrm{g} / \mathrm{mL}$ & Low solubility \\
\hline 10 to $60 \mu \mathrm{g} / \mathrm{mL}$ & Moderate Solubility \\
\hline$>60 \mu \mathrm{g} / \mathrm{mL}$ & High solubility \\
\hline
\end{tabular}

B. Stability in mouse liver microsomes:

Protocol Summary

\begin{tabular}{|l|l|}
\hline Test System & Mouse Liver Microsomes \\
\hline Test compound concentration & $1 \mu \mathrm{M}$ \\
\hline Time Points & $0,5,10,30$ and 60 minutes \\
\hline No of Replicates & Two \\
\hline Final Protein Concentration & $1 \mathrm{mg} / \mathrm{mL}$ \\
\hline Final NADPH Concentration & $1 \mathrm{mM}$ \\
\hline Potassium Phosphate Buffer $\mathrm{pH} 7.4$ & $100 \mathrm{mM}$ \\
\hline Final DMSO Concentration & $<0.1 \%$ \\
\hline Deliverables & $\begin{array}{l}\% \text { Remaining of test compound, Half } \\
\text { life, CLint }\end{array}$ \\
\hline Bioanalysis & LC-MS/MS \\
\hline Microsomes Lot no & MSO48-B \\
\hline
\end{tabular}




\begin{tabular}{|c|c|c|c|c|c|c|c|c|}
\hline Compound & $\begin{array}{l}\text { Half life } \\
\text { (min) }\end{array}$ & $\begin{array}{c}\% \text { Rem } \\
@ 60 \text { min }\end{array}$ & $\begin{array}{c}\text { \% Rem @ } 60 \\
\text { min W/O } \\
\text { Cofactor }\end{array}$ & $\begin{array}{c}\text { CL int protein } \\
(\mu \mathrm{L} / \mathrm{min} / \mathrm{mg} \\
\text { protein) }\end{array}$ & $\begin{array}{l}\text { CL int liver } \\
\text { (mL/min/g } \\
\text { liver) }\end{array}$ & $\begin{array}{c}\mathrm{CL} \text { int invivo } \\
\text { (mL/min/kg } \\
\text { BW) }\end{array}$ & $\begin{array}{c}\text { CL invivo } \\
(\mathrm{mL} / \mathrm{min} / \mathrm{kg} \mathrm{BW})- \\
\text { Well stirred } \\
\text { model }\end{array}$ & $\begin{array}{c}\text { \%QH (Well } \\
\text { stirred model) }\end{array}$ \\
\hline $20 z$ & 13.29 & 4.34 & 100.71 & 52.53 & 2.52 & 128.60 & 52.85 & 58.72 \\
\hline 26 & 282.42 & 97.98 & 110.77 & 2.52 & 0.12 & 6.17 & 5.77 & 6.41 \\
\hline $28 \mathrm{e}$ & 32.64 & 20.47 & 53.16 & 21.23 & 1.02 & 51.97 & 32.95 & 36.61 \\
\hline 30 & 66.31 & 51.45 & 104.67 & 10.46 & 0.50 & 25.60 & 19.93 & 22.14 \\
\hline Verapamil & 1.62 & 0.42 & 116.49 & 427.38 & 20.51 & 1046.22 & 82.87 & 92.08 \\
\hline
\end{tabular}

a Mean parameters throughout

\begin{tabular}{|l|c|}
\hline Classification criteria & \% QH \\
\hline Low Clearance & $<30$ \\
\hline Moderate Clearance & $30-70$ \\
\hline High Clearance & $>70$ \\
\hline
\end{tabular}


C. Permeability using MDR1-MDCKII cell monolayer:

Protocol Summary

\begin{tabular}{|l|l|}
\hline Cell origin & Solvo Biotechnology \\
\hline Test System & MDR1 MDCKII cells monolayer in 96 well format \\
\hline Passage number & 23 \\
\hline Test plate & $\begin{array}{l}\text { Poly carbonate high pore density from Millipore with } \\
0.4 \mu \mathrm{m} \text { pore size, } 0.11 \mathrm{~cm}^{2} \text { active membrane area }\end{array}$ \\
\hline Test compound concentration & $10 \mu \mathrm{M}$ \\
\hline QC Compound concentration & $10 \mu \mathrm{M}$ \\
\hline Bidirectonal assay (A-B \& B-A) time points & 0 and 120 minutes \\
\hline Receiver wells & HBSS Buffer \\
\hline Replicates & Two \\
\hline End Point & Apparent permeability (Papp) and Efflux Ratio \\
\hline Bioanalysis & LC-MS/MS \\
\hline QC Compounds & $\begin{array}{l}\text { Propranolol (High Permeable), Atenelol (Low } \\
\text { Permeable) and Digoxin (Pgp Substrate) }\end{array}$ \\
\hline Assay Type & Bi-directional (A-B and B-A) \\
\hline
\end{tabular}




\begin{tabular}{|c|c|c|c|c|c|c|}
\hline \multirow[b]{2}{*}{ Compound } & \multicolumn{2}{|c|}{ Papp $\left(10^{-6} \mathrm{~cm} / \mathrm{sec}\right)$} & \multirow[b]{2}{*}{ Efflux Ratio } & \multirow{2}{*}{$\begin{array}{l}\text { A to B \% } \\
\text { Recovery }\end{array}$} & \multirow{2}{*}{$\begin{array}{l}\text { B to A \% } \\
\text { Recovery }\end{array}$} & \multirow{2}{*}{$\begin{array}{l}\text { Permeability } \\
\text { Classification }\end{array}$} \\
\hline & $\begin{array}{l}\text { Apical to Basal Papp } \\
\left(10^{-6} \mathrm{~cm} / \mathrm{sec}\right)\end{array}$ & $\begin{array}{c}\text { Basal to Apical Papp } \\
\left(10^{-6} \mathrm{~cm} / \mathrm{sec}\right)\end{array}$ & & & & \\
\hline $20 z$ & 46.09 & 43.09 & 0.93 & 85.17 & 95.35 & High \\
\hline 26 & 39.46 & 42.61 & 1.08 & 87.37 & 96.80 & High \\
\hline $28 \mathrm{e}$ & 8.05 & 9.61 & 1.19 & 22.40 & 51.75 & Medium \\
\hline 30 & 12.63 & 18.84 & 1.49 & 39.73 & 68.52 & High \\
\hline Digoxin & 0.47 & 16.29 & 34.40 & 81.00 & 77.86 & Low \\
\hline Propranolol ${ }^{b}$ & 37.72 & 47.40 & 1.26 & 91.23 & 96.62 & High \\
\hline Atenolol ${ }^{\mathrm{c}}$ & 0.00 & 2.46 & $\mathrm{NC}$ & 114.50 & 86.38 & Low \\
\hline
\end{tabular}

\begin{tabular}{|c|c|}
\hline $\begin{array}{c}\text { Result of permeability } \\
\text { Papp (10-6 } \mathbf{c m} / \mathbf{s})\end{array}$ & Classification \\
\hline$<1.5$ & Low permeable \\
\hline 1.5 to 10 & Medium permeable \\
\hline$>10$ & High permeable \\
\hline
\end{tabular}

a Mean values throughout.

${ }^{b}$ CNS positive.

${ }^{c}$ CNS negative. 
Methods: Notum protein production, crystallization, compound soaking, data collection and structure determination.

The human Notum (UniProtKB ID: Q6P988) enzyme core sequence comprising amino acids S81-T451 with a C330S mutation ${ }^{2}$ was cloned into a stable cell line vector pNeo_sec. ${ }^{3}$ A stable HEK293S GNTI- cell4 line was obtained and used for protein production as described previously. ${ }^{5}$ The cells were expanded and grown in roller bottles (Greiner). The conditioned media were dialyzed and passed through a $5 \mathrm{ml} \mathrm{HisTrap} \mathrm{Excel} \mathrm{column}$ (GE Healthcare), followed by $20 \mathrm{mM}$ imidazole PBS wash. Notum protein was eluted with $300 \mathrm{mM}$ imidazole PBS. To remove flexible glycans, the protein was deglycosylated with endo- $\beta$-N-acetylglucosaminidase F1 $\left(37^{\circ} \mathrm{C}, 1\right.$ hour) and further purified by size-exclusion chromatography (Superdex 200 16/60 column, GE Healthcare) in $10 \mathrm{mM}$ Hepes, $\mathrm{pH}$ 7.4, $150 \mathrm{mM} \mathrm{NaCl}$ buffer.

Crystallization screening was carried out using the sitting-drop vapour diffusion method $^{6}$ in 96 -well Swissci/MRC plates. The crystallization drops contained $200 \mathrm{nl}$ of Notum $(5 \mathrm{mg} / \mathrm{ml})$ and $100 \mathrm{nl}$ of reservoir solution of $1.5 \mathrm{M}$ ammonium sulphate and $0.1 \mathrm{M}$ sodium citrate, $\mathrm{pH}$ 4.2. The crystal soaking solutions were prepared with the above reservoir solution in supplemented with compounds at concentration $5 \mathrm{mg} / \mathrm{ml}$. Crystal drops were incubated equal amount of soaking solution for 20 minutes. The soaked crystals were harvested using a MiTeGen loop and cryo-protected by immersion into reservoir solution supplemented with $25 \%(\mathrm{v} / \mathrm{v})$ ethylene glycol, then flash frozen in liquid nitrogen. Data sets were collected at temperature of $100 \mathrm{~K}$ from the Diamond Light source (Didcot UK, beamline 103, 104 and 124) and processed with Xia2. ${ }^{7}$ The structure was determined by molecular replacement with MOLREP 8 using our previously reported structure (PDB code $6 R 8 \mathrm{P}^{1}$ ) as a search model. The model was then built with $\mathrm{COOT}^{9}$ and finally refined with PHENIX.10 


\section{SI References}

1. Atkinson, B.N., Steadman, D., Zhao, Y., Sipthorp, J., Vecchia, L., Ruza, R.R., Jeganathan, F., Lines, G., Frew, S., Monaghan, A., Kjaer, S., Bictash, M., Jones, E.Y., Fish, P.V. Discovery of 2-phenoxyacetamides as inhibitors of the Wnt-depalmitoleating enzyme NOTUM from an X-ray fragment screen. Med. Chem. Commun. 2019, 10, 1361-1369.

2. Kakugawa, S., Langton, P.F., Zebisch, M., Howell, S., Chang, T.H., Liu, Y., Feizi, T., Bineva, G., O’Reilly, N., Snijders, A.P., Jones, E.Y., Vincent, J.P. NOTUM deacylates Wnt proteins to suppress signaling activity. Nature 2015, 519, 187-192.

3. Zhao, Y., Ren, J., Padilla-Parra, S., Fry, E.E., Stuart, D.I. Lysosome sorting of beta-glucocerebrosidase by LIMP-2 is targeted by the mannose 6-phosphate receptor. Nat Commun 2014, 5, 4321.

4. Reeves, P.J., Callewaert, N., Contreras, R., Khorana, H.G. Structure and function in rhodopsin: high-level expression of rhodopsin with restricted and homogeneous $\mathrm{N}$-glycosylation by a tetracycline-inducible $\mathrm{N}$ acetylglucosaminyltransferase I-negative HEK293S stable mammalian cell line. Proceedings of the National Academy of Sciences of the United States of America 2002, 99, 13419-13424.

5. Zhao, Y., Ren, J., Hillier, J., Jones, M., Lu, W., Jones, E.Y. Structural characterisation of melatonin as an inhibitor of the Wnt deacylase Notum. J. Pineal Res. 2020, 68, e12630.

6. Walter, T.S., Diprose, J.M., Mayo, C.J., Siebold, C., Pickford, M.G., Carter, L., Sutton, G.C., Berrow, N.S., Brown, J., Berry, I.M., Stewart-Jones, G.B., Grimes, J.M., Stammers, D.K., Esnouf, R.M., Jones, E.Y., Owens, R.J., Stuart, D.I., Harlos, K. A procedure for setting up high-throughput nanolitre crystallization experiments. Crystallization workflow for initial screening, automated storage, imaging and optimization. Acta Crystallogr D Biol Crystallogr 2005, 61, 651-657.

7. Winter, G., Lobley, C.M., Prince, S.M. Decision making in xia2. Acta Crystallogr D Biol Crystallogr 2013, 69, 1260-1273.

8. Vagin, A., Teplyakov, A. Molecular replacement with MOLREP. Acta Crystallogr D Biol Crystallogr 2010, $66,22-25$.

9. Emsley, P., Cowtan, K. Coot: model-building tools for molecular graphics. Acta Crystallogr D Biol Crystallogr 2004, 60, 2126-2132.

10. Afonine, P.V., Grosse-Kunstleve, R.W., Echols, N., Headd, J.J., Moriarty, N.W., Mustyakimov, M., Terwilliger, T.C., Urzhumtsev, A., Zwart, P.H., Adams, P.D. Towards automated crystallographic structure refinement with phenix.refine. Acta Crystallogr D Biol Crystallogr 2012, 68, 352-367. 